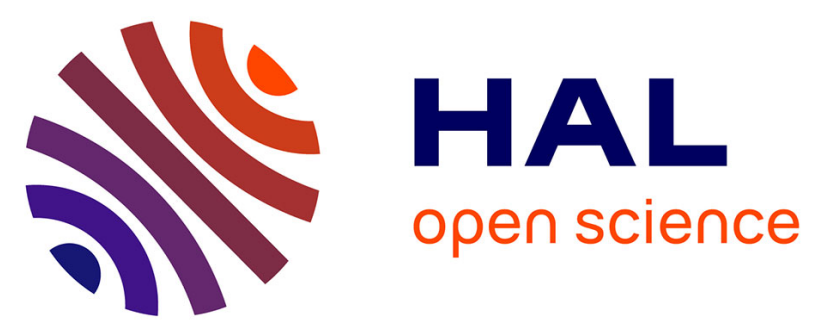

\title{
Enhanced and preferential internalization of lipid nanocapsules into human glioblastoma cells: effect of a surface-functionalizing NFL peptide
}

Reatul Karim, Elise Lepeltier, Lucille Esnault, Pascal Pigeon, Laurent Lemaire, Claire Lépinoux-Chambaud, Nicolas Clere, Gérard Jaouen, Joël Eyer, Géraldine Piel, et al.

\section{To cite this version:}

Reatul Karim, Elise Lepeltier, Lucille Esnault, Pascal Pigeon, Laurent Lemaire, et al.. Enhanced and preferential internalization of lipid nanocapsules into human glioblastoma cells: effect of a surfacefunctionalizing NFL peptide. Nanoscale, 2018, 10, pp.13485-13501. 10.1039/C8NR02132E . hal01817763

\section{HAL Id: hal-01817763 \\ https://hal.sorbonne-universite.fr/hal-01817763}

Submitted on 6 Sep 2018

HAL is a multi-disciplinary open access archive for the deposit and dissemination of scientific research documents, whether they are published or not. The documents may come from teaching and research institutions in France or abroad, or from public or private research centers.
L'archive ouverte pluridisciplinaire HAL, est destinée au dépôt et à la diffusion de documents scientifiques de niveau recherche, publiés ou non, émanant des établissements d'enseignement et de recherche français ou étrangers, des laboratoires publics ou privés. 
6 Reatul Karim, ${ }^{a b}$ Elise Lepeltier, ${ }^{*}{ }^{*}$ Lucille Esnault, ${ }^{a}$ Pascal Pigeon, ${ }^{c d}$ Laurent Lemaire, ${ }^{a}$

7 Claire Lépinoux-Chambaud, ${ }^{a}$ Nicolas Clere, ${ }^{a}$ Gérard Jaouen, ${ }^{c}$ Joel Eyer, ${ }^{a}$ Géraldine Piel, ${ }^{b}$

8 and Catherine Passirani ${ }^{a}$

$9 \quad{ }^{\mathrm{a}}$ MINT, UNIV Angers, INSERM 1066, CNRS 6021, Angers, France

$10{ }^{\mathrm{b}}$ LTPB, CIRM, University of Liège, Liège, Belgium

$11{ }^{\mathrm{c}}$ PSL Chimie ParisTech, 11 Rue Pierre \& Marie Curie, F-75005 Paris, France

$12 \mathrm{~d}$ Sorbonne Université, Université Pierre et Marie Curie, CNRS, Institut Parisien de Chimie

13 Moléculaire (IPCM, UMR 8232), F-75005, Paris France

14 * Corresponding author: elise.lepeltier@univ-angers.fr 


\section{ABSTRACT}

2 Increasing intracellular drug concentration using nanocarriers can be a potential strategy to

3 improve efficacy against glioblastoma (GBM). Here, the fluorescent-labelled NFL-TBS.40-63

4 peptide (fluoNFL) concentration on lipid nanocapsule (LNC) was studied to enhance nanovector

5 internalization into human GBM cells. The LNC surface-functionalization with various fluoNFL

6 concentrations was performed by adsorption. LNC size and surface charge altered gradually with

7 increasing peptide concentration, but their complement protein consumption remained low.

8 Desorption of fluoNFL from LNC surface was found to be slow. Furthermore, it was observed

9 that the rate and extent of LNC internalization in the U87MG human glioblastoma cells were

10 dependent on the surface-functionalizing fluoNFL concentration. In addition, we showed that the

11 uptake of fluoNFL-functionalized LNCs was preferential towards U87MG cells compared to

12 healthy human astrocytes. The fluoNFL-functionalized LNC internalization into the U87MG

13 cells was energy-dependent and occurred possibly by macropinocytosis, clathrin-mediated and

14 caveolin-mediated endocytosis. A new ferrocifen-type molecule (FcTriOH), as potent anticancer

15 candidate, was then encapsulated in the LNCs and the functionalization improved its in vitro

16 efficacy compared to other tested formulations against U87MG cells. In the preliminary study,

17 on subcutaneous human GBM tumor model in nude mice, a significant reduction of relative

18 tumor volume was observed at one week after the second intravenous injection with FcTriOH-

19 loaded LNCs. These results showed that enhancing NFL peptide concentration on LNC surface

20 is a promising approach for increased and preferential nanocarrier internalization into human

21 GBM cells, and the FcTriOH-loaded LNCs are promising therapy approach for GBM. 
1 Keywords: lipid nanocapsule, glioblastoma, ferrocifen, cell-penetrating peptide, NFL-TBS.4063.

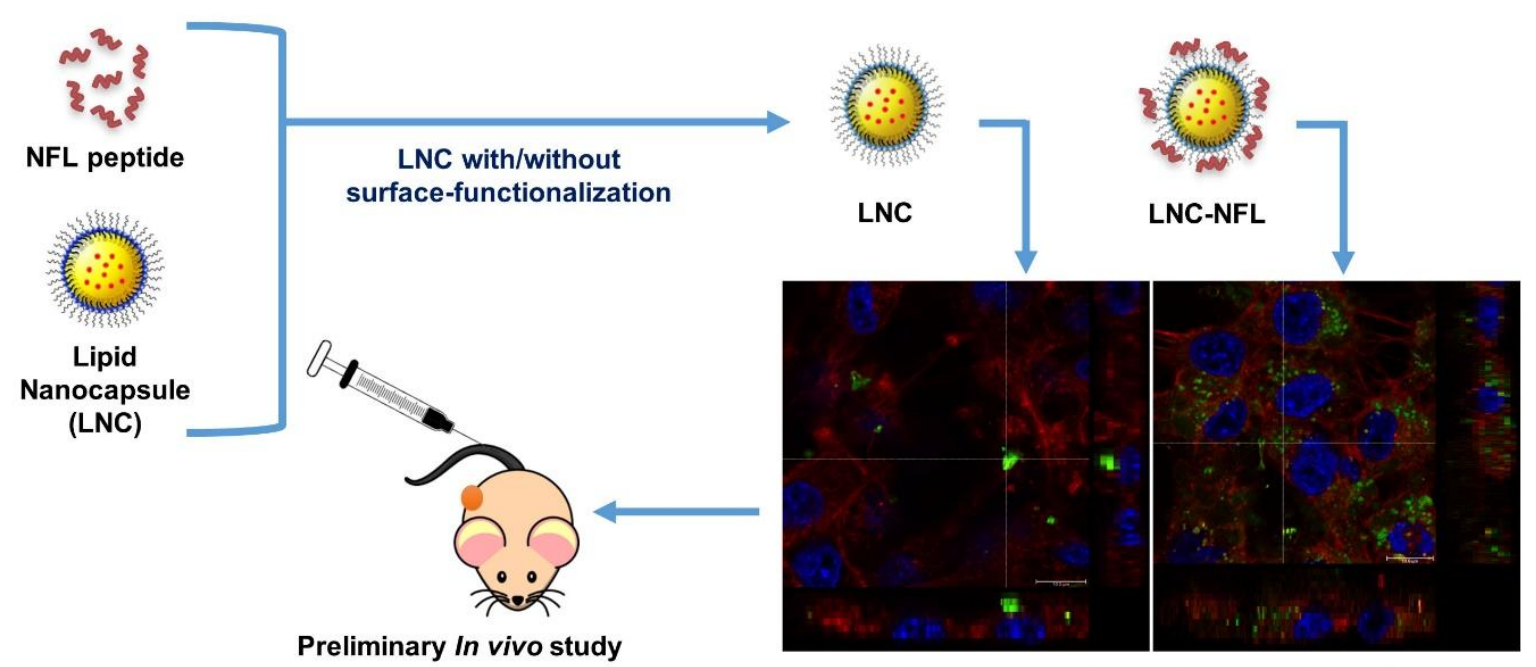

In vitro evaluation on human GBM cells

8 Surface functionalized LNC showed a preferential internalization into GBM cells and 9 demonstrated a significant decrease of the tumor volume. 


\section{INTRODUCTION}

3 Glioblastoma multiforme (GBM) is one of the most prevalent, and fatal primary brain tumors

4 classified as the World Health Organization as a grade IV CNS tumor. ${ }^{1}$ Although remarkable

5 progress in diagnostic methods and treatment strategies has been achieved in the last few

6 decades, the median survival only altered from 8.3 to 14.6 months over the last 60 years after

7 present multimodal therapy (surgical resection followed by radiotherapy plus chemotherapy)..$^{2-4}$

8 Therefore, new therapeutic approaches for treatment of GBM are necessary.

$9 \quad$ Nanosized-drug delivery systems (NDDSs) have appeared as a promising strategy for drug

10 delivery against cancer, including brain cancers. The NDDSs can have numerous beneficial

11 characteristics i.e. prolonged blood circulation time, improved bioavailability of hydrophobic

12 drugs, controlled drug release and site-targeted drug delivery. ${ }^{5}$ Moreover, long circulating

13 nanocarriers with appropriate size may accumulate in malignant brain tumors after crossing the

14 integrity impaired blood-brain barrier $(\mathrm{BBB})$ by enhanced permeability and retention (EPR)

15 effect, and improve survival time of animals. ${ }^{6}$ Among various nanocarriers, lipid nanocapsules

16 (LNCs) have been reported in numerous literatures as promising NDDS for carrying

17 hydrophobic drugs due to their characteristic oily core. ${ }^{7}$ One of the promising features of LNC

18 formulation is its easy and organic solvent free preparation technique that can be easy to scale-up

19 for future industrial purpose. ${ }^{8}$ LNCs were evaluated and showed promising in vitro and in vivo

20 results against GBM in numerous studies. ${ }^{9-11}$ A novel ferrocifen-type anticancer molecule, 4-

21 ferrocenyl-5,5-bis(4-hydroxyphenyl)-pent-4-en-1-ol (FcTriOH) (Fig. 1), was encapsulated in the

22 LNCs. The FcTriOH belongs to the newer hydroxypropyl series of ferrocifens which can convert

23 into novel tetrahydrofuran-substituted quinone methide. ${ }^{12-13}$ Compared to the corresponding

24 acyclic series ferrocifen, FcTriOH showed about 6-folds lower $\mathrm{IC}_{50}(0.11 \pm 0.02 \mu \mathrm{M})$ against 
1 estrogen-receptor-negative breast cancer cells possibly due to the reduced polarity of the

2 intrinsically antiproliferative quinone methide (by cyclization of the hydroxyalkyl chain). ${ }^{12}$ In

3 this study, the in vitro antiproliferative activity of the FcTriOH-loaded LNCs was thus studied on

4 another cell line : U87MG human GBM cells.

5 In order to enhance intracellular drug concentrations into GBM cells, the LNC surface can be

6 modified by adding various GBM-targeting ligands. ${ }^{14-17}$ A neurofilament light subunit derived 24

7 amino acid tubulin binding site peptide called NFL-TBS.40-63 (NFL) was reported to

8 preferentially be internalized into human, rat and mouse GBM cells compared to corresponding

9 healthy cells. ${ }^{18}$ This peptide was evaluated as potential GBM-targeting moiety on LNC surface in

10 rat or mouse GBM cell lines. ${ }^{19-20}$ However, based on these studies and in order to be more

11 clinically relevant, it is necessary to evaluate the internalization capability of NFL-functionalized

12 LNCs into human GBM cells. Moreover, the concentration of the GBM targeting ligand should

13 also be optimized to achieve enhanced and preferential delivery to GBM cells. Therefore, the

14 aim of this study was to evaluate the effect of the LNC surface-adsorbed NFL concentration on

15 the nanovector internalization into human GBM cells, in order to achieve a preferential uptake

16 and avoid potential toxicity on healthy cells. The effect of NFL adsorption on the

17 physicochemical characteristics of LNC was studied. Additionally, impact of salt concentrations

18 on NFL-desorption from the LNC surface was studied. Moreover, influence of peptide-

19 adsorption on the complement protein consumption by the formulations was investigated. A

20 comparative cellular internalization kinetic study into human GBM cells with the various

21 developed LNCs was performed and confirmed by confocal microscopy study. Targeting ability

22 of the NFL-functionalized LNCs towards GBM cells was also assessed by comparing its uptake

23 into both GBM cells and astrocytes under identical conditions. Possible internalization pathway 
1 of the functionalized-LNC into the human GBM cell line was assessed. Finally, a preliminary in

2 vivo study was performed on an ectopic human GBM tumor model in mice in order to observe

3 possible therapeutic effects after systemic delivery of the formulations.

4

11 occurred by adsorption. ${ }^{19,} 22$ The initial molar concentration of NFL peptide for the LNC-

12 fluoNFL1 was kept same as previously published literatures $(1 \mathrm{mM})^{19,22}$ whereas it was 3-folds

13 higher in LNC-fluoNFL2. Final concentrations of the adsorbed fluoNFL $(\% \mathrm{w} / \mathrm{w})$, determined by 14 HPLC, on LNC-fluoNFL1 and LNC-fluoNFL2 was of $0.40 \pm 0.01 \%$ and $2.49 \pm 0.01 \%$ 15 respectively.

16 Particle size, PDI and zeta potential of the different nanocapsule formulations determined by 17 Dynamic Light Scattering (DLS) and laser Doppler electrophoresis are given in Table 1. The 18 investigational conditions, i.e. LNC concentrations, sample viscosities, temperature and sample 
1 conductivity were consistent among the measurements. The control LNC had a size of $57 \pm 2$

$2 \mathrm{~nm}$, PDI of $0.08 \pm 0.01$ and zeta potential of $-2.2 \pm 0.9 \mathrm{mV}$. LNC-fluoNFL1 had a size of $61 \pm 1$

$3 \mathrm{~nm}$, PDI of $0.12 \pm 0.02$ and zeta potential of $0.5 \pm 0.7 \mathrm{mV}$ (Table 1). Additionally, LNC-

4 fluoNFL2 had the highest values among the three formulations i.e. size of $64 \pm 1 \mathrm{~nm}$, PDI of

$5 \quad 0.15 \pm 0.02$ and zeta potential of $4.9 \pm 1.5 \mathrm{mV}$.

6 Encapsulation of FcTriOH in LNC (LNC-FcTriOH) significantly $(\mathrm{p}<0.001)$ reduced the

7 particle size to $50 \pm 2 \mathrm{~nm}$, compared to control LNC. Drug-loading of LNC-FcTriOH was 2.67

$8 \%(\mathrm{w} / \mathrm{w})$ with an encapsulation efficiency of $99.8 \pm 2.3 \%$. After fluoNFL adsorption, the size of

9 LNC-FcTriOH-fluoNFL2 was $58 \pm 1 \mathrm{~nm}$ which was significantly $(\mathrm{p}<0.001)$ larger compared to

10 LNC-FcTriOH. PDI and zeta potential was not altered after FcTriOH encapsulation with/without

11 fluoNFL functionalization compared to respective unloaded LNCs.

12

13 Table 1: Physicochemical characteristics of the nanocapsules

\begin{tabular}{llll}
\hline Formulation & Size $(\mathrm{nm})$ & PDI & Zeta potential $(\mathrm{mV})$ \\
\hline Control LNC & $57 \pm 2$ & $0.08 \pm 0.01$ & $-2.2 \pm 0.9$ \\
LNC -fluoNFL1 & $61 \pm 1^{* *}$ & $0.12 \pm 0.02^{* *}$ & $0.5 \pm 0.7^{* *}$ \\
LNC-fluoNFL2 & $64 \pm 1^{* * *}$ & $0.15 \pm 0.02^{* * *}$ & $4.9 \pm 1.5^{* * *}$ \\
LNC-FcTriOH & $50 \pm 2^{* * *}$ & $0.06 \pm 0.02$ & $-2.3 \pm 1.3$ \\
$\begin{array}{l}\text { LNC-FcTriOH- } \\
\text { fluoNFL2 }\end{array}$ & $58 \pm 1$ & $0.15 \pm 0.08^{*}$ & $3.4 \pm 0.6^{* * *}$
\end{tabular}

14 (Oneway ANOVA with Dunnett's post-test. $\mathrm{p}<0.05$ is denoted by $\left(^{*}\right), \mathrm{p}<0.01$ by $\left(^{* *}\right)$ and $\mathrm{p}$ $15<0.001$ by $(* * *), \mathrm{n}=6)$

16

17 Interaction between LNCs and fluoNFL 
1 The interaction between the LNC surface and NFL peptide in a formulation equivalent to

2 LNC-fluoNFL1 was described previously. ${ }^{22}$ To understand the interaction between the LNC

3 surface and fluoNFL, the LNC-fluoNFL2 and LNC as control were incubated for $30 \mathrm{~min}$ in

4 UPW and different concentrations of $\mathrm{NaCl}$ or Tris buffer $\mathrm{pH}$ 7.4. Subsequently, their size was

5 measured in DLS (Fig. 2). The size of LNC-fluoNFL2 remained significantly different compared

6 to control $\mathrm{LNCs}$ as $\mathrm{NaCl}$ concentration was increased up to $1 \mathrm{mM}$. However, as concentration of

7 Tris buffer increased above $0.05 \mathrm{M}$, the size of LNC-fluoNFL2 was reduced and its significant

8 difference compared to control LNCs was lost.
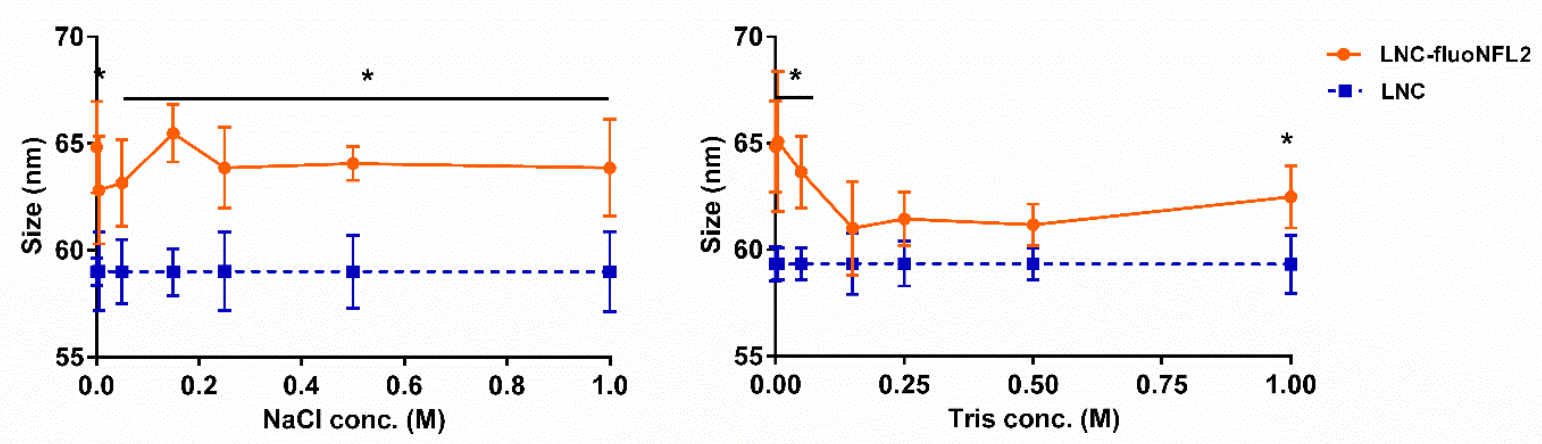

11 Figure 2: Mean particle sizes of control LNCs and LNC-fluoNFL2 in various concentrations of

$12 \mathrm{NaCl}$ and Tris buffer (t-test. $\mathrm{p}<0.05$ is denoted by $(*), \mathrm{p}<0.01$ by $(* *)$ and $\mathrm{p}<0.001$ by $(* * *), \mathrm{n}$ $13=3)$.

14 Moreover, LNC-fluoNFL2 was dialyzed against $0.05 \mathrm{M}$ Tris buffer at $37^{\circ} \mathrm{C}$ and $75 \mathrm{rpm}$ using 15 a dialysis bag having MWCO $100 \mathrm{kD}$. At various time points, the amount of fluoNFL in the 16 receiver chamber (desorbed from the formulation) was quantified by HPLC. As control, the 17 peptide solution was dialyzed and quantified in the receiver chamber. The control peptide 18 solution reached the receiver chamber very quickly and more than $90 \%$ of the peptide was 
1 recovered by $1 \mathrm{~h}$. However, a slow and gradual desorption of the peptide was observed (Fig. 3)

2 from the LNC surface and only $6 \%$ peptide desorption occurred by 30 min and reached $33 \%$ by $36 \mathrm{~h}$.

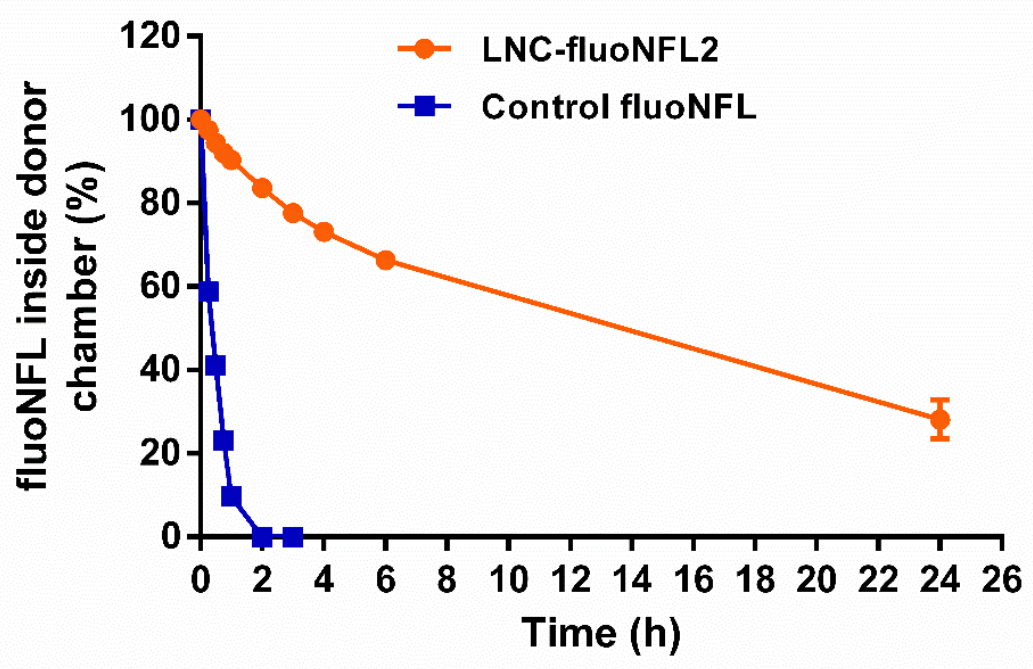

5 Figure 3: FluoNFL desorption kinetics from LNC-fluoNFL2 surface in $0.05 \mathrm{M}$ Tris buffer $\mathrm{pH}$

$6 \quad 7.4$ at $37^{\circ} \mathrm{C}$ and $75 \mathrm{rpm}$.

7 Complement consumption by the nanocapsules

8 Complement consumption by the control LNCs and the fluoNFL-functionalized LNCs was

9 assessed by the CH50 assay. The particle concentration in the control LNCs was quantified by

10 NTA and was used to calculate surface area of the LNC formulations. The percentage of CH50

11 unit consumptions by the control LNCs, and the peptide functionalized LNCs were plotted

12 against surface area of the nanocapsules in $1 \mathrm{~mL}$ of NHS (Fig. 4). The complement consumption

13 by all three nanocapsules increased as surface area of the nanovectors increased per mL of NHS.

14 The percentage of CH50 unit consumption by control LNCs and LNC-fluoNFL1 was similar and

15 reached only 9.8 and $7.6 \%$ respectively at around $700 \mathrm{~cm}^{2} / \mathrm{mL}$ NHS. The complement 
1 consumption by LNC-fluoNFL2 was slightly higher and reached $21.0 \%$ at the same surface

2 area.

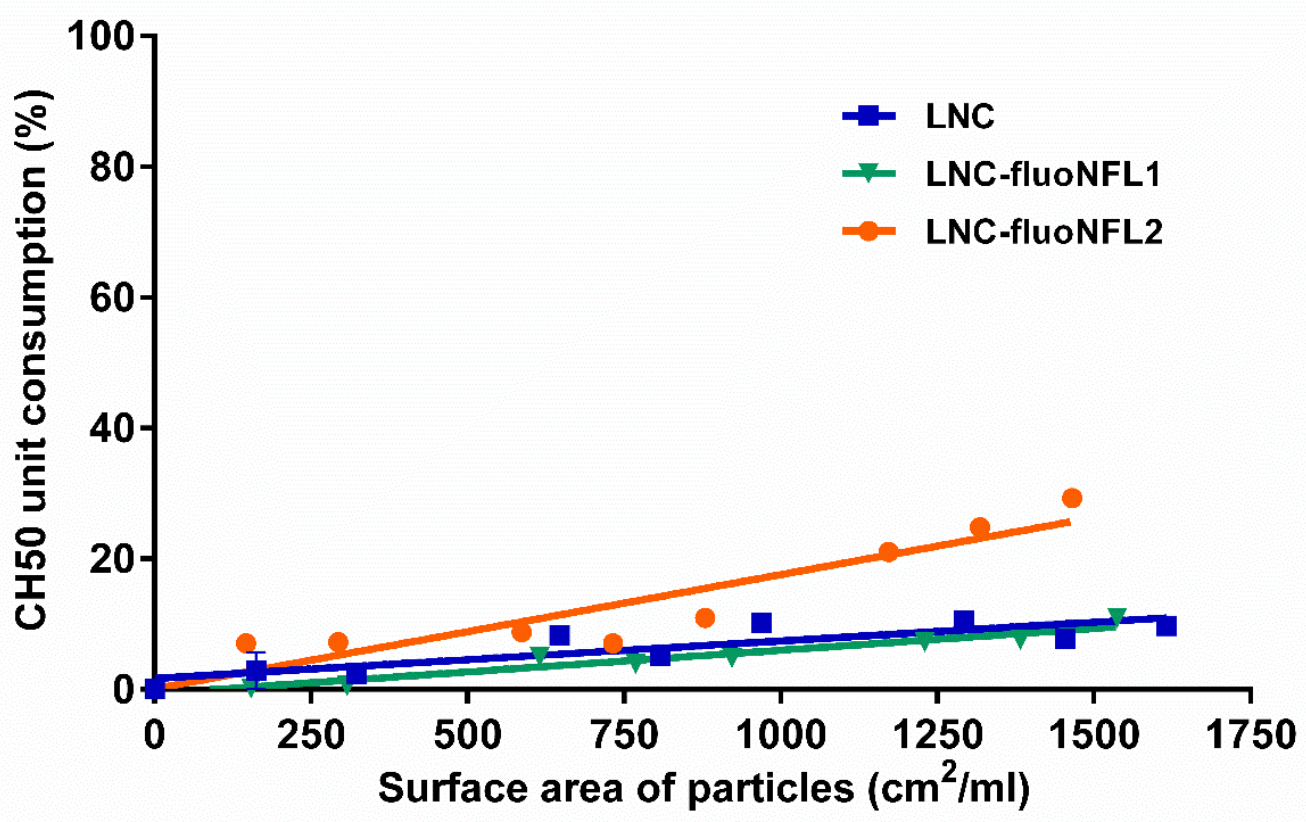

4 Figure 4: Complement consumption at $37{ }^{\circ} \mathrm{C}$ by control LNCs, LNC-fluoNFL1 and LNC5 fluoNFL2.

6 Effect of surface-functionalizing fluoNFL concentration on LNC internalization into 7 human GBM cells

$8 \quad$ LNC concentration used for the cellular uptake studies was $1.23 \mathrm{mg} / \mathrm{mL}$ (corresponds to 11.1 $9 \mu \mathrm{M}$ NFL in LNC-fluoNFL2), which was primarily selected based on previously described safe 10 concentrations of LNCs and NFL peptide. ${ }^{19,22-23}$ Moreover, results of the MTS assays on 11 U87MG cells treated with the peptide solutions or blank LNCs showed that cell viability did not 12 decrease at these concentrations (Supporting Information: Fig. S1 and S2). The U87MG cells 13 were treated with DiA-labelled LNCs (LNC-DiA, LNC-DiA-fluoNFL1 and LNC-DiA14 fluoNFL2) for $30 \mathrm{~min}, 1 \mathrm{~h}, 6 \mathrm{~h}$ and $24 \mathrm{~h}$ to assess their cellular internalization at each time point 
1 (Fig. 5). For each formulation, the cellular uptake increased as time was increased, showing the

2 time dependency of the cell internalization. The internalization of LNC-DiA was of 0.2, 0.8, 2.3

3 and $11.8 \%$ after $30 \mathrm{~min}, 1 \mathrm{~h}, 6 \mathrm{~h}$ and $24 \mathrm{~h}$ respectively. LNC-DiA-fluoNFL1 uptake was 1.2 ,

$42.7,46.5$ and $81.9 \%$ after $30 \mathrm{~min}, 1 \mathrm{~h}, 6 \mathrm{~h}$ and $24 \mathrm{~h}$ respectively; whereas it was $8.4,16.6,72.4$

5 and $86.2 \%$ for LNC-DiA-fluoNFL2. At each time point, the cellular internalization of LNC-

6 DiA-fluoNFL2 was significantly higher compared to LNC-DiA-fluoNFL1 and LNC-DiA, 7 whereas uptake of LNC-DiA-fluoNFL1 was significantly higher compared to LNC-DiA.

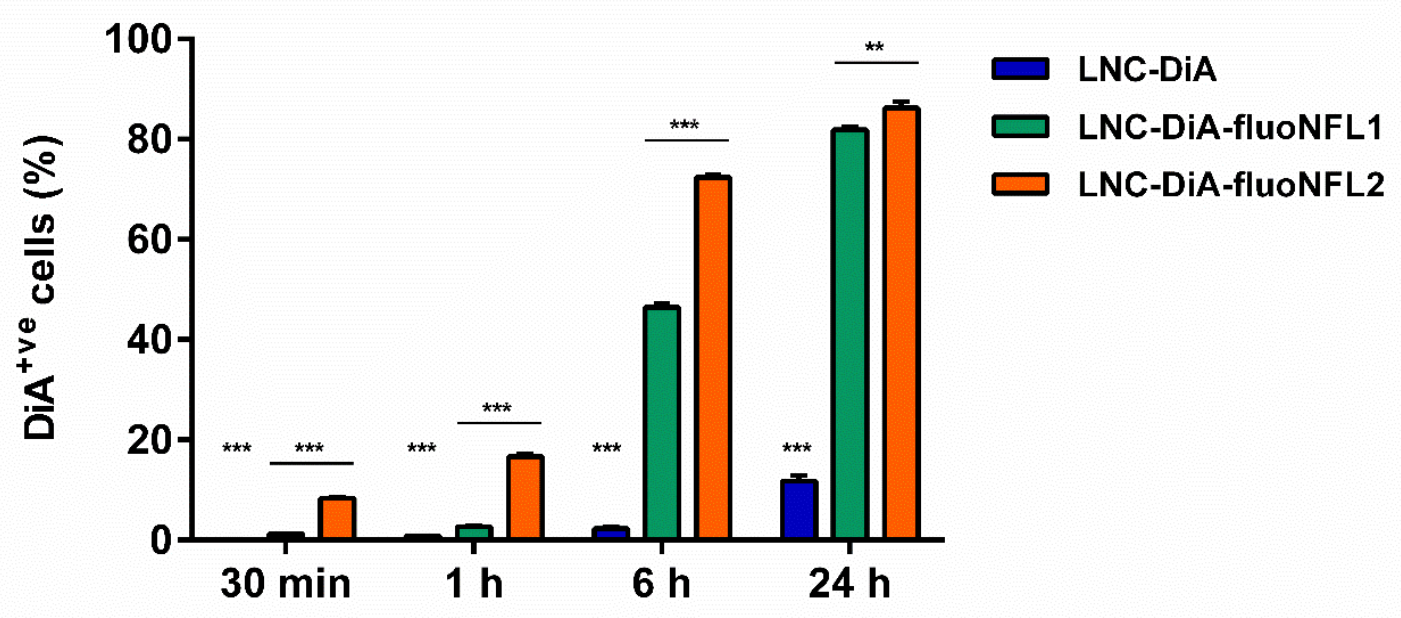

9 Figure 5. Enhancement of LNC internalization at $37{ }^{\circ} \mathrm{C}$ into U87MG cells with increasing 10 concentration of the fluoNFL peptide on LNC surface. The cells were incubated with 1.23

$11 \mathrm{mg} / \mathrm{mL}$ of LNC-DiA, LNC-DiA-NFL1 and LNC-DiA-fluoNFL2 for $30 \mathrm{~min}, 1 \mathrm{~h}, 6 \mathrm{~h}$ and $24 \mathrm{~h}$.

12 Twenty thousand events per sample were analyzed and percentages of $\mathrm{DiA}^{+\mathrm{ve}}$ cells were

13 measured. The experiments were performed in triplicate. Statistical analysis was performed with

14 one-way ANOVA with Tukey post-hoc test $\left(\mathrm{p}<0.05\right.$ is denoted by $\left(^{*}\right), \mathrm{p}<0.01$ by $\left(^{* *}\right)$ and $\mathrm{p}$ $15<0.001$ by $(* * *), n=3)$. 
1 Moreover, to investigate the necessity of the peptide adsorption on LNC (during the

2 formulation of LNC-fluoNFL2) to enhance its cellular uptake, DiA-labelled LNC and fluoNFL

3 (at same peptide concentration as LNC-DiA-fluoNFL2) were mixed to prepare 'LNC-DiA \&

4 fluoNFL imm. mix.' and the cells were treated immediately for $1 \mathrm{~h}$ at $37^{\circ} \mathrm{C}$. The uptake of the

5 immediate mixture was significantly lower (3.9-folds) compared to LNC-DiA-fluoNFL2, but

6 slightly higher compared to LNC-DiA (Fig. 6).

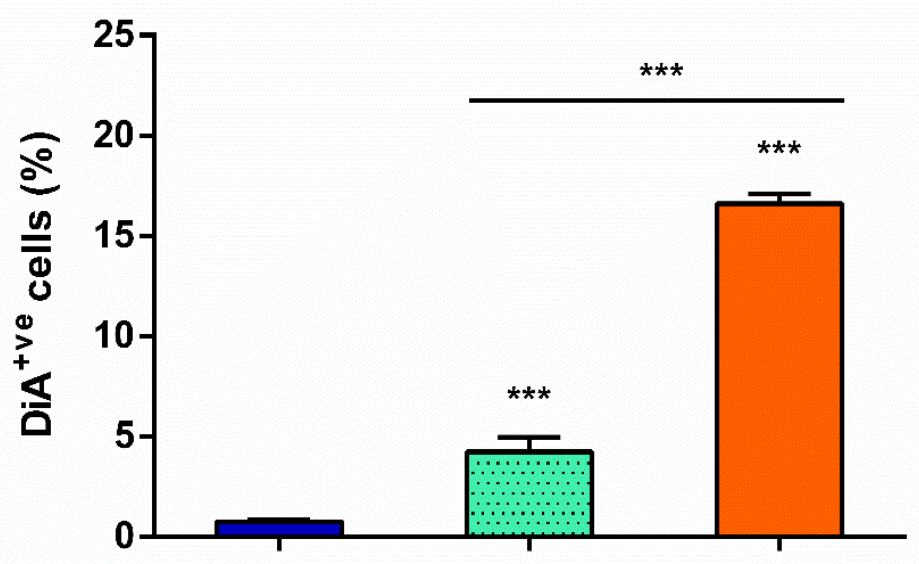

$\square$ LNC-DiA

L... LNC-DiA \& fluoNFL (imm. mix.)

$\square$ LNC-DiA-fluoNFL2

8 Figure 6: Internalization of LNC-DiA, immediate mixture of LNC-DiA and fluoNFL2, and

9 LNC-DiA-fluoNFL2 into U87MG cells at $37{ }^{\circ} \mathrm{C}$ after $1 \mathrm{~h}$. The cells were incubated with 1.23

$10 \mathrm{mg} / \mathrm{mL}$ of LNC-DiA, 'LNC-DiA \& fluoNFL imm. mix.' and LNC-DiA-fluoNFL2 for $1 \mathrm{~h}$.

11 Twenty thousand events per sample were analyzed and percentage of $\mathrm{DiA}^{+\mathrm{ve}}$ cells was measured.

12 The experiments were performed in triplicate. Statistical analysis was performed with oneway

13 ANOVA with Tukey post-hoc test $(\mathrm{p}<0.05$ is denoted by $(*), \mathrm{p}<0.01$ by (**) and $\mathrm{p}<0.001$ by $14(* * *), \mathrm{n}=3)$.

15 Additionally, the higher cellular internalization of LNC-fluoNFL2 compared to control LNCs 16 was visualized by confocal microscopy (Fig. 7). The cells were first treated by LNC-DiA (green 17 dye) and LNC-DiA-fluoNFL2 (green dye) for $6 \mathrm{~h}$, followed by staining of their nuclei (DAPI 
1 staining: blue) and cytoskeleton (phalloidin-TRITC staining: red) for capturing confocal images.

2 The DiA signal was much higher for the fluoNFL-functionalized LNCs compared to control

3 LNCs, and almost each cell had DiA signal in its cytoplasm.

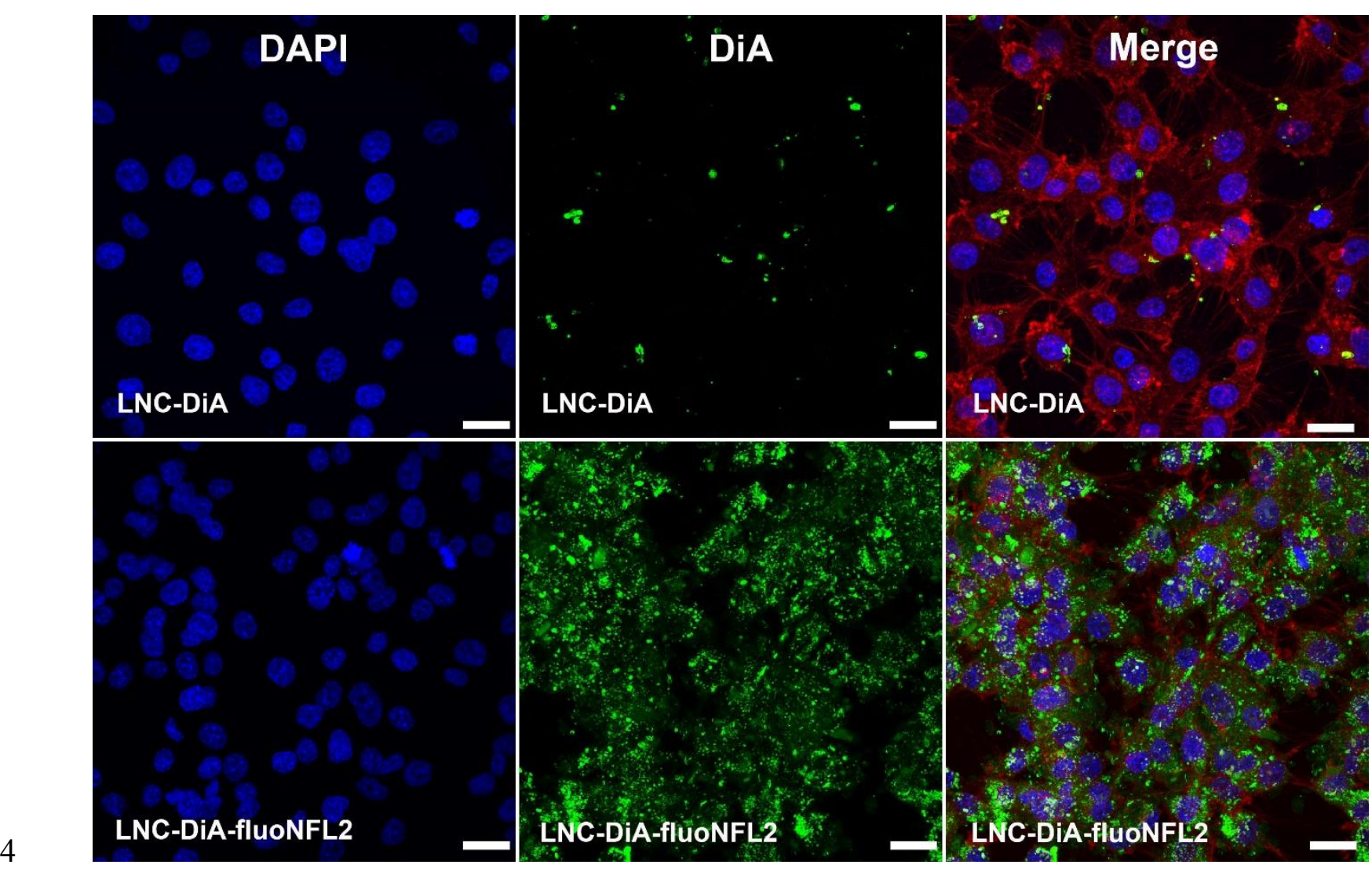

5 Figure 7. Representative confocal microscopy images of enhanced LNC internalization into

6 U87MG cells due to LNC surface-functionalizing fluoNFL peptide. Cells were treated at $37{ }^{\circ} \mathrm{C}$

7 for $6 \mathrm{~h}$ with $1.23 \mathrm{mg} / \mathrm{mL}$ of LNC-DiA and LNC-DiA-fluoNFL2. Blue is DAPI staining (nuclei),

8 green is DiA (LNC) and red is phalloidin-TRITC staining (F-actin, cytoskeleton). White bar $=20$

$9 \mu \mathrm{m}$. Supporting information: Fig. S3.

10 To visualize if the LNCs were on the cell surface or inside the cytoplasm, orthogonal sections

11 of the stacked images were analyzed (Fig. 8). Indeed, nearly all the fluorescence was observed

12 inside the cytoplasm of the cells and each cell had internalized lots of NFL functionalized 
2 rather than inside the cytoplasm.

LNC-DiA

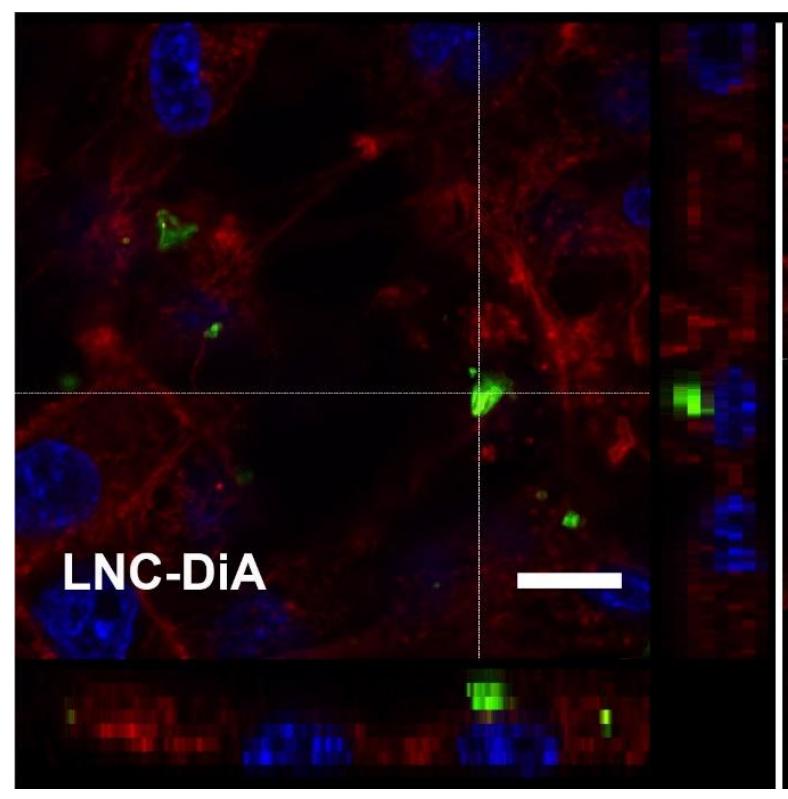
$\mu \mathrm{m}$.

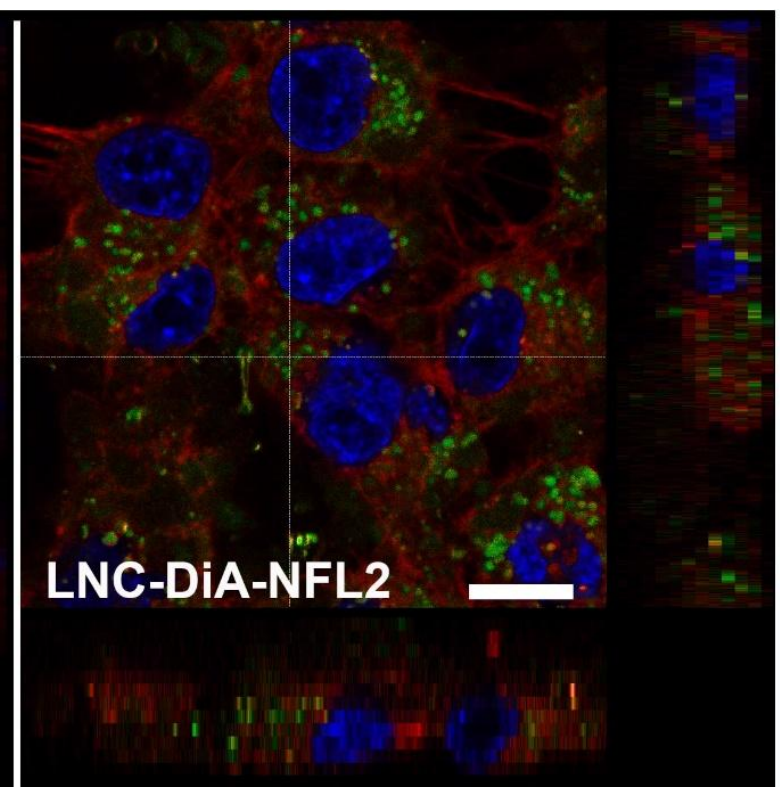

Figure 8. Orthogonal sections of stacked confocal microscopy images showing LNC

internalization into U87MG cells. Majority of LNC-DiA-NFL2 was localized into cell cytoplasm, whereas LNC-DiA was chiefly localized on cell surface. The cells were treated at 37 ${ }^{\circ} \mathrm{C}$ for $6 \mathrm{~h}$ with $1.23 \mathrm{mg} / \mathrm{mL}$ of LNC-DiA and LNC-DiA-NFL2. Blue is DAPI staining (nuclei), green is DiA (LNC) and red is phalloidin-TRITC staining (F-actin, cytoskeleton). White bar $=10$

15 in Normal Human Astrocytes (NHA) compared to U87MG cells at $1 \mathrm{~h}$ and $6 \mathrm{~h}$ (Fig. 9). Surface-

16 functionalization with the fluoNFL peptide significantly enhanced the uptake of LNCs in NHA 
1 by 5.2 -folds and 3.5 -folds at $1 \mathrm{~h}$ and $6 \mathrm{~h}$ respectively, compared to control LNCs (LNC-DiA)

2 (Fig. S4). In contrast, LNC functionalization with fluoNFL enhanced the LNC uptake into

3 U87MG cells by 21.6-folds and 31.5-folds at $1 \mathrm{~h}$ and $6 \mathrm{~h}$ respectively, compared to control LNCs.

4 Although there was no significant difference of LNC-DiA-fluoNFL2 internalization in NHA and 5 U87MG cells at $1 \mathrm{~h}$, the uptake was significantly higher (4.4-folds) in the GBM cells by $6 \mathrm{~h}$.
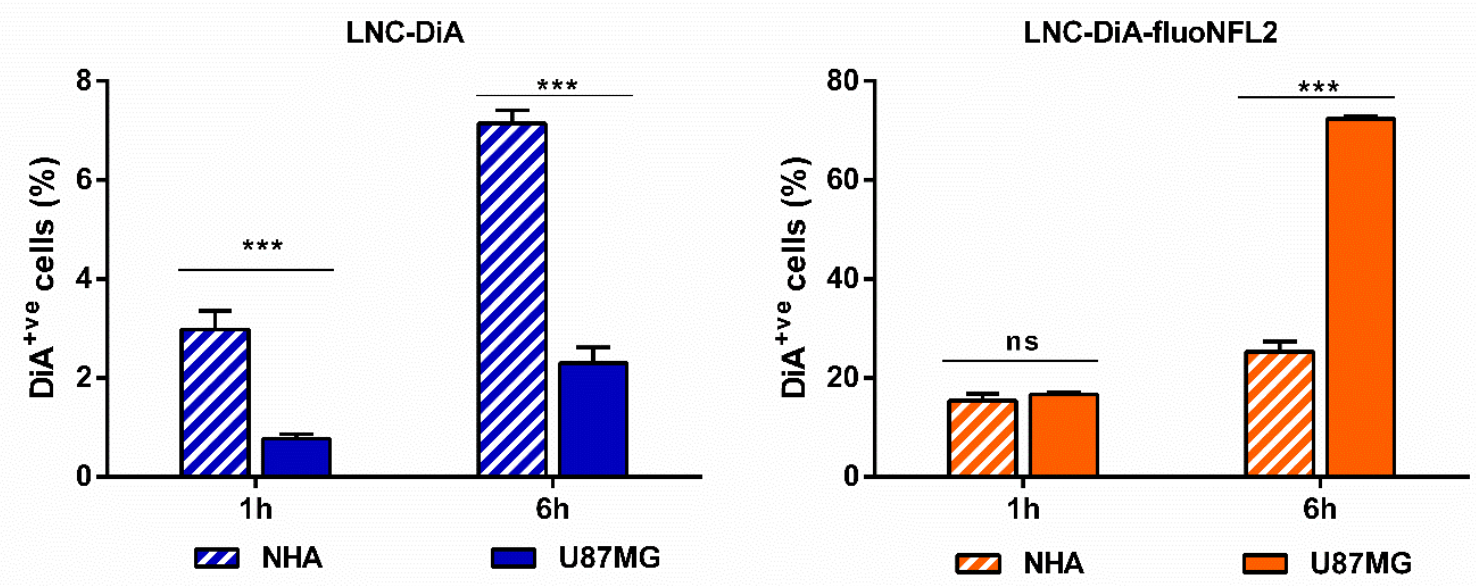

7 Figure 9: Higher LNC-DiA internalization into NHA compared to U87MG cells, whereas LNCDiA-fluoNFL2 was internalized preferentially into U87MG cells compared to NHA. The cells

9 were incubated with $1.23 \mathrm{mg} / \mathrm{mL}$ of LNC-DiA or LNC-DiA-fluoNFL2 for $1 \mathrm{~h}$ and $6 \mathrm{~h}$. Twenty

10 thousand events per sample were analyzed and percentages of $\mathrm{DiA}^{+\mathrm{ve}}$ cells were measured. The

11 experiments were performed in triplicate. Statistical analysis was performed with t-test $(\mathrm{p}<0.05$

12 is denoted by $(*), p<0.01$ by $(* *)$ and $p<0.001$ by $(* * *), n=3)$. Supporting Information: Fig. S4.

13 Mechanisms of fluoNFL-functionalized lipid nanocapsule internalization in U87MG

14 human glioblastoma cell

15 To evaluate the possible mechanism of LNC-fluoNFL2 internalization in U87MG cells, the 16 cells were treated with the DiA-labelled nanocapsules in different energetic conditions i.e. at $4^{\circ} \mathrm{C}$ 17 and ATP-depleted conditions for $1 \mathrm{~h}$ and $6 \mathrm{~h}$ (Fig. 10a). At $4^{\circ} \mathrm{C}$, the internalization of LNC-DiA- 
1 fluoNFL2 was almost completely stopped both at $1 \mathrm{~h}$ and $6 \mathrm{~h}$ and therefore the alteration was

2 significant compared to the normal conditions (n.c.). In ATP-depleted conditions, LNC-DiA-

3 fluoNFL2 uptake was near $0 \%$ after $1 \mathrm{~h}$, but increased to about $25 \%$ of the n.c after $6 \mathrm{~h}$. At $1 \mathrm{~h}$,

4 the LNC-DiA-fluoNFL2 uptake was similar in both conditions $\left(4{ }^{\circ} \mathrm{C}\right.$ and ATP-depleted), but

5 significantly different after $6 \mathrm{~h}$. Internalization of fluoNFL solution was significantly and

6 similarly reduced at $4^{\circ} \mathrm{C}$ and in ATP-depleted condition at $1 \mathrm{~h}$ compared to n.c. (Fig. 10b).

7 Therefore, LNC-fluoNLF2 uptake in U87MG cells was temperature and energy-dependent

8 process, similarly to fluoNFL as previously reported. ${ }^{18}$

a)

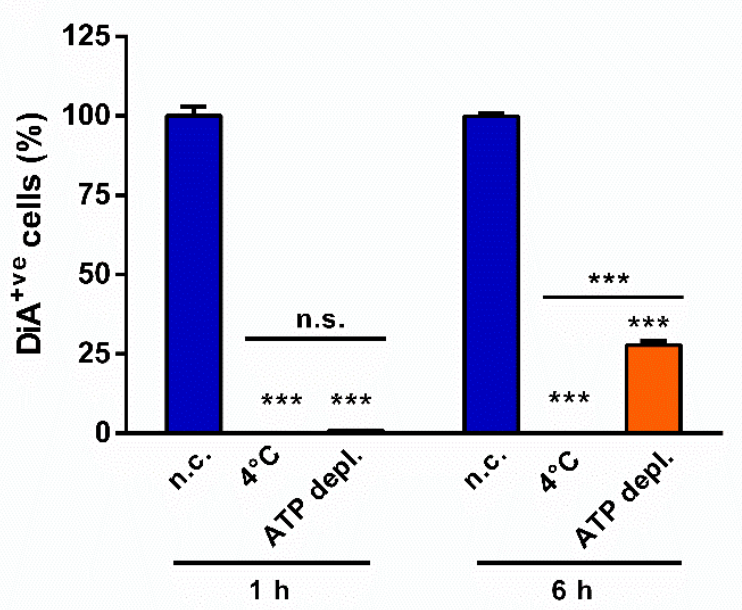

b)

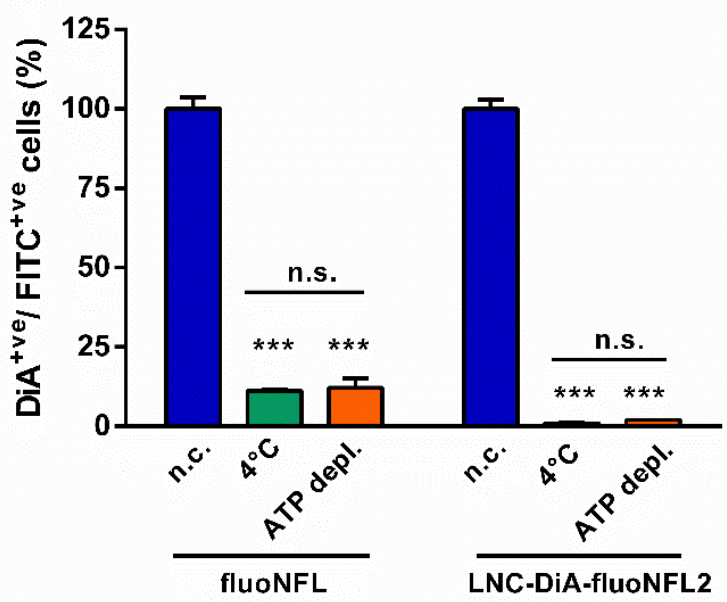

10 Figure 10: a) LNC-DiA-fluoNFL2 internalization into U87MG cells at different energetic

11 conditions. The cells were incubated with $1.23 \mathrm{mg} / \mathrm{mL}$ of LNC-DiA-fluoNFL2 for $1 \mathrm{~h}$ and $6 \mathrm{~h}$ at

$1237{ }^{\circ} \mathrm{C}$ (n.c.), $4^{\circ} \mathrm{C}$ and ATP-depleted conditions. b) Comparison of internalization of fluoNFL and

13 LNC-DiA-fluoNFL2 in U87MG cells at different energetic conditions at $1 \mathrm{~h}$. Twenty thousand

14 events per sample were analyzed and percentages of DiA ${ }^{+v e}$ cells (for LNC-DiA-fluoNFL2) or

$15 \mathrm{FAM}^{+\mathrm{ve}}$ cells (for fluoNFL) were measured. The experiments were performed in triplicate. 
1 Statistical analysis was performed with oneway ANOVA with Tukey post-hoc test $(p<0.05$ is

2 denoted by $(*), \mathrm{p}<0.01$ by $(* *)$ and $\mathrm{p}<0.001$ by $(* * *), \mathrm{n}=3)$.

3 To further evaluate the possible uptake pathway(s) of the peptide-functionalized LNCs,

4 exclusion of particular endocytosis mechanisms was achieved by using inhibitors of the foremost

5 endocytosis pathways. The cells were pretreated for 30 minutes with different inhibitors

6 followed by $1 \mathrm{~h}$ treatment with the LNC-DiA-NFL2. LNC uptake was significantly inhibited in

7 presence of each of these inhibitors (Fig. 11a). LNC-DiA-NFL2 internalization was the lowest in

8 presence of DAM, followed by $\mathrm{CP}, \mathrm{M} \beta \mathrm{CD}$ and PMA. A strong correlation between fluoNFL

9 internalization and LNC-DiA-fluoNLF2 uptake was observed (Fig. 11b). Like the

10 functionalized-LNC, fluoNFL uptake was most strongly inhibited by DAM, followed by similar 11 inhibition in presence of $\mathrm{CP}$ and $\mathrm{M} \beta \mathrm{CD}$, and lastly PMA.

a)

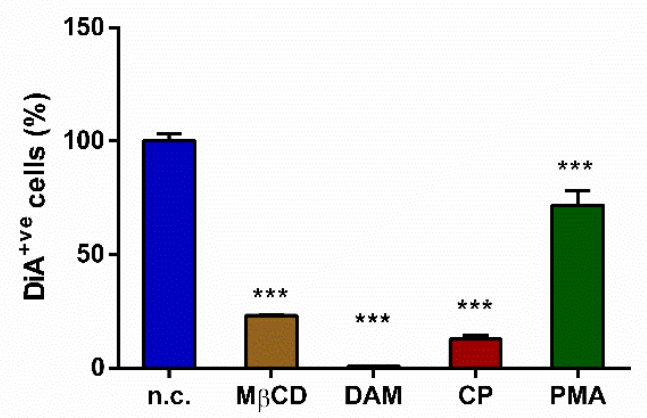

b)

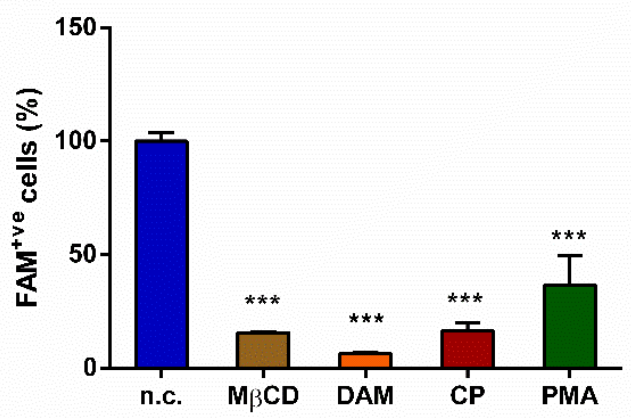

13 Figure 11: Internalization of LNC-DiA-fluoNFL2 (a) and fluoNFL (b) into U87MG cells at 37

$14{ }^{\circ} \mathrm{C}$ (n.c.) after 30 min pretreatment with various inhibitors (M $\beta C D$, DAM, CP and PMA)

15 followed by $1 \mathrm{~h}$ incubation with the nanocapsule $(1.23 \mathrm{mg} / \mathrm{mL})$ or the peptide solution

16 (equivalent fluoNFL concentration of LNC-DiA-fluoNFL2). Twenty thousand events per sample

17 were analyzed and percentages of $\mathrm{DiA}^{+\mathrm{ve}}$ cells (for LNC-DiA-fluoNFL2) or $\mathrm{FAM}^{+\mathrm{ve}}$ cells (for

18 fluoNFL) were measured. The experiments were performed in triplicate. Statistical analysis was 
1 performed with oneway ANOVA with Dunnett's post-hoc test ( $\mathrm{p}<0.05$ is denoted by $(*)$, p

$2<0.01$ by $(* *)$ and $\mathrm{p}<0.001$ by $(* * *), \mathrm{n}=3)$.

\section{In vitro efficacy on U87MG cells}

4 To evaluate the in vitro efficacy of FcTriOH loaded LNC formulations, cell viability was

5 evaluated by MTS assay after $72 \mathrm{~h}$ of treatment with the formulations (Fig. 12). The $\mathrm{IC}_{50}$ of

6 FcTriOH solution was of $1.31 \mu \mathrm{M}$ which was slightly reduced to $1.05 \mu \mathrm{M}$ when the drug was

7 loaded in LNC. However, the peptide-functionalized LNC-FcTriOH-NFL2 had the lowest $\mathrm{IC}_{50}$

8 of $0.46 \mu \mathrm{M}$, which was 2.8 -folds and 2.3-folds lower compared to the drug solution and the drug-

9 loaded non-functionalized LNCs (LNC-FcTriOH). The blank LNCs showed toxicity at much

10 higher concentrations $\left(\mathrm{IC}_{50} 1.42 \mathrm{mg} / \mathrm{mL}\right.$ ) compared to the drug-loaded LNCs (Supporting 11 information: Fig. S1). The fluoNFL solution did not show any toxicity in the tested

12 concentrations (Supporting information: Fig. S2).

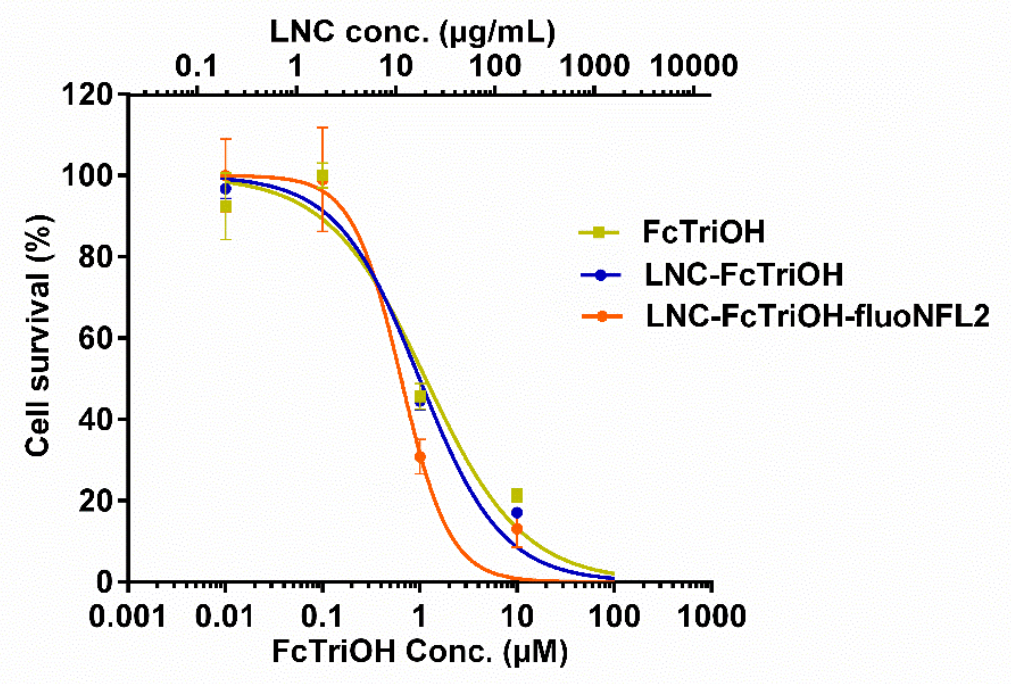

13

14 Figure 12. Survival percentages of U87MG cells after $72 \mathrm{~h}$ treatment with various 15 concentrations of LNCs (LNC, LNC-FcTriOH and LNC-FcTriOH-NFL2) and FcTriOH solution. 
$4 \quad$ Preliminary in vivo study in ectopic tumor xenograft model

5 Nude NMRI mice were subcutaneously inoculated with human U87MG cells to acquire

6 preliminary knowledge of possible tumor reduction efficacy and toxicity of the developed

7 formulations after i.v. administration. After 7 days of cell implantation, the average tumor

8 volume was around $70 \mathrm{~mm}^{3}$ and the animals were divided into five groups (saline, LNC-blank,

9 LNC-blank-fluoNFL2, LNC-FcTriOH and LNC-FcTriOH-fluoNFL2) and injected intravenously

10 with $70 \mu \mathrm{L}$ of treatments (20 mg FcTriOH per $\mathrm{kg}$ body weight, or $822.4 \mathrm{mg} \mathrm{LNCs}$ with/without

$1121.5 \mathrm{mg}$ peptide per $\mathrm{kg}$ of body weight) on day 7 and day 10 (Fig. 13). The relative tumor

12 volume of the saline and the LNC-blank treated mice gradually increased from day 7 until the

13 end of the study, whereas it was stable until day 17 and then increased for LNC-blank-fluoNFL2

14 treated group. For the FcTriOH treated groups (LNC-FcTriOH and LNC-FcTriOH-fluoNFL2),

15 relative tumor volume gradually decreased up to day 17 , remained smaller than their initial

16 volume (at the first treatment injection day) up to day 22, and then increased gradually.

17 Compared to saline treated group, the relative tumor growth for LNC-FcTriOH and LNC-

18 FcTriOH-fluoNFL2 treated groups were significantly lower (40.1 and $44.2 \%$ lower respectively)

19 at day 17 of the study (Fig. 13). This significant difference was maintained up to day 22 of the

20 study, and was absent afterwards.

21 None of the mice showed any immediate or delayed behavioral signs of pain or toxicity after

22 the treatments were administered. Moreover, they were growing gradually as evident from their

23 relative weight which increased about $20 \%$ at the end of the study period (day=50): Fig. 13. 


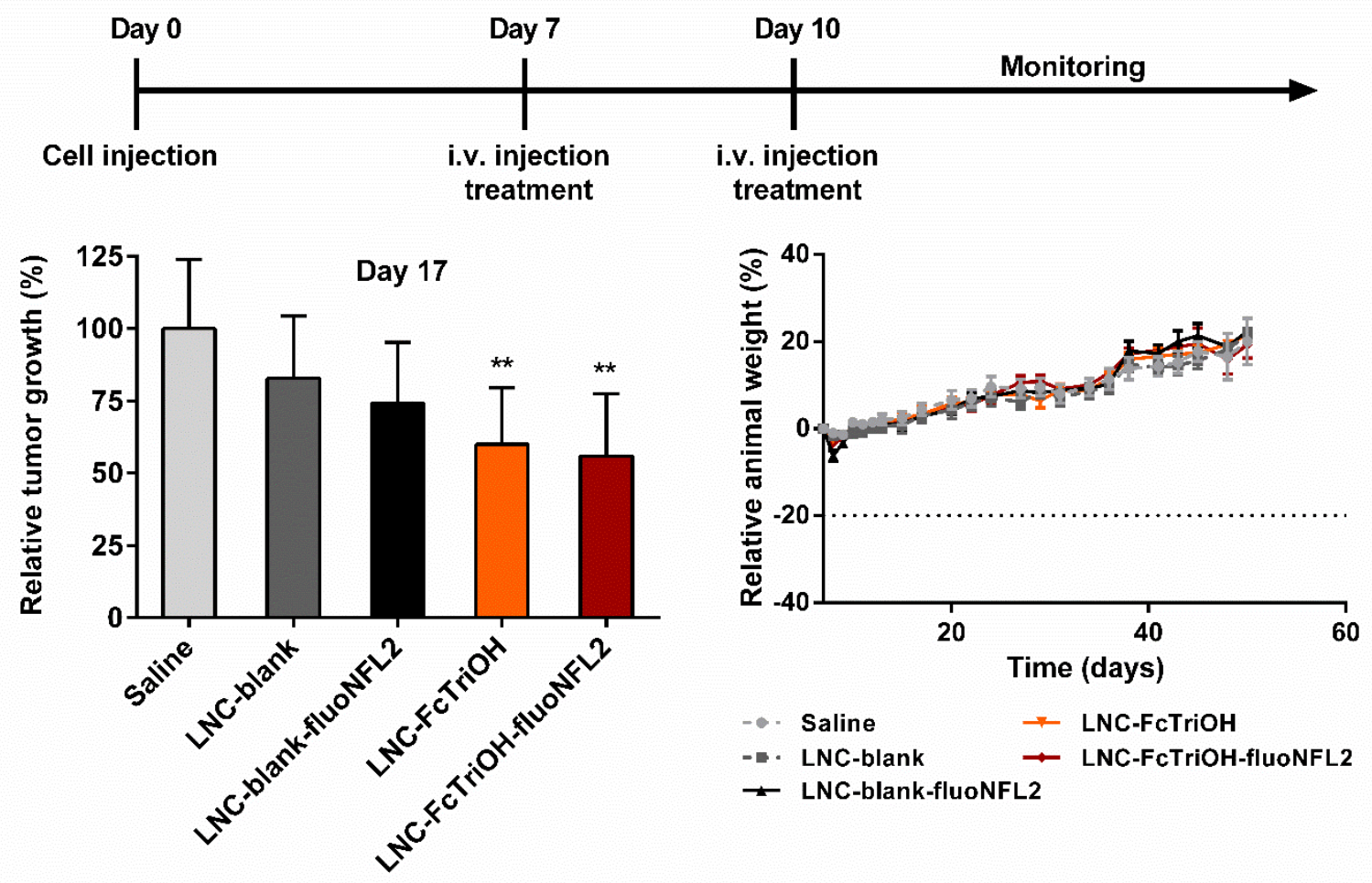

2 Figure 13: Relative tumor growth (on day 17) and relative animal weight of subcutaneous

3 U87MG human glioblastoma tumor bearing mice. Each mouse was injected with $2 \times 10^{6}$ cells (in

$450 \mu \mathrm{L}$ PBS) in the right flank on day 0 of the study. As the average tumor volume reached about

$570 \mathrm{~mm}^{3}$ after one week, the mice received their treatment (equivalent to $20 \mathrm{mg}$ FcTriOH per $\mathrm{kg}$

6 of body weight) by i.v. injections on day 7 and day 10. Mouse weight, behavior and tumor

7 volume was followed regularly. Statistical analysis was performed with one-way ANOVA with

8 Dunnett post-hoc test ( $\mathrm{p}<0.05$ is denoted by $(*), \mathrm{p}<0.01$ by $(* *)$ and $\mathrm{p}<0.001$ by $(* * *), \mathrm{n}=7$ for

9 saline, $\mathrm{n}=8$ for other groups)

\section{DISCUSSION}

11 The aim of this study was to evaluate the effect of surface-functionalizing fluoNFL peptide

12 concentration on LNC internalization into human GBM cells, in order to improve their efficacy

13 as a drug delivery system for GBM. LNCs are promising nanovectors for carrying hydrophobic 
1 anticancer molecules and has been used in numerous preclinical studies using various GBM

2 tumor models and different administration routes. ${ }^{9,}{ }^{24-25}$ However, GBM tumors are known to

3 develop resistance to such treatments. ${ }^{26}$ Therefore, enhancement of cellular internalization of

4 LNCs into GBM cells by functionalizing their surface can be a promising approach to improve

5 therapeutic efficacy. The NFL peptide was reported to preferentially enter in GBM cells from

6 diverse origins (human, rat and mouse) compared to corresponding healthy cerebral cells, and

7 reduced cell viability at $\geq 100 \mu \mathrm{M} .{ }^{18}$ Moreover, treatment with NFL-functionalized LNCs

8 encapsulating an anticancer molecule (e.g. ferrocifens) which has a different mechanism of

9 action than the peptide may improve therapeutic outcomes by limiting resistance development by

10 GBM cells. The potential of this peptide as a GBM-targeting ligand to functionalize LNC surface

11 was investigated by Balzeau et al., and increased cellular uptake of LNCs into mouse GBM

12 cells. ${ }^{19}$ In this study, the capability of NFL-peptide to act as a targeting ligand for the U87MG

13 human GBM cells and the effect of surface-functionalizing NFL concentration on cellular

14 internalization of LNCs were evaluated. Finally, the efficacy of NFL-LNCs encapsulating a

15 ferrocifen-type anticancer molecule, FcTriOH, was tested.

16 Covalent coupling of the peptide on distal end of PEG chains was not performed as it

17 diminished the GBM targeting capability of NFL. ${ }^{19}$ Therefore, surface-functionalization of LNCs

18 was performed by simply adsorbing different amounts of the peptide onto LNC surface over $24 \mathrm{~h}$

19 period. As size, zeta potential and surface coating can profoundly impact on the in vivo fate of

20 the nanovectors, ${ }^{27}$ these properties of the developed LNCs were characterized (Table 1). The

21 particle size of the control LNCs was $57 \pm 2 \mathrm{~nm}$, whereas diameter of the LNC-fluoNFL1 (NML

$221 \mathrm{mM}$ ) and LNC-fluoNFL2 (NFL $3 \mathrm{mM}$ ) were about $4 \mathrm{~nm}$ and $7 \mathrm{~nm}$ larger respectively

23 signifying a potential higher amount of fluoNFL adsorbed to the surface. Similarly, peptide 
1 adsorption increased the zeta potential of the LNC-fluoNFL1 and LNC-fluoNFL2 by +2 and +7

$2 \mathrm{mV}$ respectively compared to control LNC. This variation of surface charge can be explained by

3 the net positive charge of the NFL peptide at physiological $\mathrm{pH}^{28}$ The changes in size and zeta

4 potential for LNC-fluoNFL1 were similar to the one reported by Carradori et al. ${ }^{22}$ Moreover, the

5 LNC size after fluoNFL adsorption was well below $100 \mathrm{~nm}$ which can be beneficial for diffusion

6 in the cerebral extracellular space. ${ }^{9,}{ }^{29}$ The PDI of all three formulations were less than 0.2 ,

7 therefore they can be considered as monodispersed. The concentration of the LNC-adsorbed

8 fluoNFL was quantified indirectly by measuring the free peptide concentration after separating

9 them using centrifugal filters with MWCO $100 \mathrm{kD}$. The concentration of LNC-adsorbed peptide

10 in LNC-fluoNFL1 was $0.40 \% \mathrm{w} / \mathrm{w}$ which was in correspondence with the concentration

11 reported by Balzeau et al. and Carradori et al. ${ }^{19,22}$ The concentration of LNC adsorbed fluoNFL

12 in LNC-fluoNFL2 was $2.49 \%(\mathrm{w} / \mathrm{w})$ which was about 6-folds higher compared to LNC-

13 fluoNFL1 although the concentration of peptide initially added was only 3 -folds higher. The

14 number of peptide molecules per LNC particle can be calculated from the particle concentration

15 obtained by NTA and the adsorbed NFL concentration quantified by HPLC. About 240 and 1530

16 peptides were adsorbed per LNC particle in LNC-fluoNFL1 and LNC-fluoNFL2 respectively.

17 Torchilin et al. determined the number of TAT peptides on $200 \mathrm{~nm}$ liposomes by radiolabeling

18 the peptide and measuring liposome-associated radioactivity. About 500 peptides per liposome

19 was calculated, ${ }^{30}$ which was included in the range of fluoNFL chains used in our formulations.

20 About 0.016 and 0.102 fluoNFL molecules will be present per $\mathrm{nm}^{2}$ surface area in LNC-

21 fluoNFL1 and LNC-fluoNFL2 respectively, whereas up to 5.4 short chain PEG molecules

22 (comes from Kolliphor HS15) per $\mathrm{nm}^{2}$ surface area can be present in average. The exact reason

23 for such high percentage of adsorption is unknown. It can be hypothesized that 3 -folds increased 
1 peptide concentration during the $24 \mathrm{~h}$ adsorption step possibly increased the likelihood of

2 collision and amplified the LNC-peptide and peptide-peptide interactions, which in combination

3 may have resulted in the high percentage of NFL adsorption. Physical entanglement between

4 adjacent peptide molecules might also occur in presence of LNCs at this concentration, resulting

5 restrained peptide movement and increased adsorption. ${ }^{31}$ Moreover, the aqueous dispersion of

6 LNCs became a gel after adsorption by an initial concentration of $4 \mathrm{mM}$ fluoNFL (therefore NFL

7 concentrations above $3 \mathrm{mM}$ were not tested). This also indicated that the peptide-LNC mixture

8 may start to form a rigid network at high peptide concentrations. Self-assembly of peptides has

9 been described to form hydrogels in the literature. ${ }^{32}$ Alteration in environmental conditions (e.g.

$10 \mathrm{pH}$ and ionic strength) can trigger interaction among peptide chains resulting physical cross-

11 linking and filament growth to form viscoelastic solids. ${ }^{33}$ Addition of LNC dispersion may alter

12 such environmental conditions of the peptide solution and result formation of semi-solids.

13 Balzeau et al. has reported that the NFL interacts with the polar PEG chains of the Kolliphor ${ }^{19}$

14 whereas Carradori et al. suggested that the interaction was possibly by a combination of

15 electrostatic forces and other weak forces i.e. Van der Waal's forces and hydrophobic forces. ${ }^{22}$

16 We evaluated the effect of $\mathrm{NaCl}$ and Tris buffer concentration on LNC-fluoNFL2 size by

17 incubation with different concentrations of these solutions and subsequently measuring their

18 diameter in DLS (Fig. 2). Contrasting to previous studies, the significant difference of

19 nanocapsule diameter compared to control LNCs was maintained nearly throughout the $\mathrm{NaCl}$

20 concentration range. However, Tris buffer impacted more the size of LNC-fluoNFL2 compared

21 to $\mathrm{NaCl}$, and no significant difference of particle size was observed above $0.05 \mathrm{M}$ concentration.

22 It can be hypothesized that the possible self-entanglement of the peptide in LNC-fluoNFL2

23 involves more inter-chain interactions (e.g. hydrogen bond, hydrophobic forces and/or Van der 
1 Waal's forces) and therefore resisted the impact of high $\mathrm{NaCl}$ concentrations, but loses its

2 significant size difference with control LNCs in higher Tris concentrations. To evaluate if the

3 fluoNFL will be rapidly removed from the LNC surface after dilution, LNC-fluoNFL2 was

4 dialyzed (MWCO $100 \mathrm{kD}$ dialysis bag) against $1 \mathrm{x}$ Tris buffer solution at $37^{\circ} \mathrm{C}$ and $75 \mathrm{rpm}$. Free

5 peptide concentration was quantified from the receiver compartment by HPLC. Desorption of the

6 fluoNFL from LNC surface was slow and gradual and only $33.6 \%$ peptide was desorbed after 6

7 h (Fig. 3). Moreover, NFL-functionalized LNCs was reported to maintain their characteristics in

8 cell culture medium. ${ }^{22}$ Therefore, the LNC-fluoNFL2 formulation can be promising for

9 administration by i.v. injection. Additionally, this dialysis experimentation also indicated a high

10 percentage of fluoNFL adsorption in LNC-fluoNFL2. About $94.4 \%$ and $90.4 \%$ of the added

11 peptide were remaining in the dialysis chamber after $30 \mathrm{~min}$ and $1 \mathrm{~h}$ dialysis respectively for

12 LNC-fluoNFL2, whereas it was only $41.1 \%$ and $9.6 \%$ for the control fluoNFL solution (same

13 initial concentration as LNC-fluoNFL2). Theoretically, up to $58.9 \%$ of the added $3 \mathrm{mM}$ peptide

14 in LNC-fluoNFL2 should be able to cross the dialysis membrane to reach the receiver chamber

15 after $30 \mathrm{~min}$ dialysis, if they were free. Therefore, this result also showed that the peptide

16 adsorption percentage in LNC-fluoNFL2 was possibly very high and strongly attached to the

17 LNC surface and further study is necessary to understand the real mechanism.

18 As the size and zeta potential of the LNCs was altered after fluoNFL adsorption, it could

19 impact the in vivo fate of the nanocarrier. Enhanced particle size and positive zeta potential may

20 significantly increase complement protein consumption by nanoparticles, leading to rapid

21 removal from systemic circulation by the mononuclear phagocytic system (MPS). ${ }^{34-35}$ The CH50

22 unit consumption by the LNC-fluoNFL1 was similar to what shown by the control LNCs (Fig.

23 4). However, the $\mathrm{CH} 50$ unit consumption by the LNC-fluoNFL2 was slightly enhanced 
1 compared to the other two formulations. This can be attributed to the increased size as surface

2 area recognition by the complement is proportional to the particle diameter, ${ }^{36}$ or to the altered

3 zeta potential. ${ }^{35}$ Overall, the complement consumption by all three formulations was low even at

4 high surface area (calculated by NTA) ${ }^{37}$ and should not be quickly removed from bloodstream by 5 MPS.

6 Previously, Balzeau et al. showed that the internalization of LNC in mouse GBM cells can be 7 enhanced by adsorbing the NFL peptide on its surface. ${ }^{19}$ However, cellular uptake on 8 nanocarriers can be cell specific as the interacting plasma membrane composition (i.e. ligands, 9 receptors and endocytosis apparatus) vary among cell lines. ${ }^{38}$ Therefore, as a potential 10 therapeutic strategy for human disease, it was necessary to characterize the internalization 11 kinetics of the LNC with/without the surface-adsorbed NFL peptide in a human GBM cell line at 12 a non-toxic concentration. Moreover, Lépinoux-Chambaud et al. reported that the extent and 13 pathway of NFL internalization into U87MG cells were dependent on the extracellular peptide 14 concentration. ${ }^{23}$ Therefore, the effect of LNC surface-functionalizing fluoNFL peptide 15 concentration on LNC internalization by U87MG human GBM cells was evaluated in this study.

16 For this purpose, the LNCs were fluorescently labelled by encapsulation of a hydrophobic dye, 17 DiA, and their cellular uptake was quantified by fluorescence-activated cell sorting (FACS). The 18 LNC concentration used for the cellular uptake studies was $1.23 \mathrm{mg} / \mathrm{mL}$, having $11.1 \mu \mathrm{M}$ of 19 NFL-peptide in LNC-fluoNFL2. The blank LNCs and the peptide solutions were non-toxic at 20 these concentrations as observed in the MTS assays (Supporting Information: Fig. S1 and S2). 21 To identify and separate dead cells, the FACS samples were suspended in $0.12 \% \mathrm{w} / \mathrm{v}$ of trypan 22 blue for the measurements in flow cytometer and signals in $655 \mathrm{~nm}$ long-pass filter was detected. 23 Trypan blue can enter inside cells with damaged membrane, complex with proteins and emit 
1 fluorescence around $660 \mathrm{~nm}$ that can be detected in FACS. ${ }^{39-40}$ However, maximum $0.1 \%$ dead

2 cells were detected in the FACS samples which confirms that the LNC concentration used for

3 treatment of cells was non-toxic. The internalization of all three formulations increased with time

4 (Fig. 5). At each time point, the uptake of LNC-DiA-fluoNFL2 was significantly higher

5 compared to LNC-DiA-fluoNFL1 and LNC-DiA, whereas the internalization of LNC-DiA-

6 fluoNFL1 was significantly higher compared to LNC-DiA. It was also observed that the peptide

7 needs to be absorbed onto the LNC surface (by $24 \mathrm{~h}$ stirring) for maximizing LNC

8 internalization as the uptake of 'LNC-DiA and fluoNFL immediate mixture' was significantly

9 lower compared to LNC-DiA-fluoNFL2 (Fig. 6). Therefore, the internalization of nanocapsules

10 into U87MG cells is dependent on the concentration of NFL on LNC surface. Confocal

11 microscopy images visually confirmed the much higher cellular uptake of LNC-DiA-fluoNFL2

12 compared to LNC-DiA (Fig. 7), and showed that majority of the NFL-functionalized LNCs was

13 into the cytoplasm whereas the LNC-DiA was mostly attached to the cell membrane (Fig. 8). It

14 has been shown for the first time that the NFL peptide concentration (as a targeting-ligand) onto

15 nanocarrier surface can have significant impact on the rate and the extent of the nanovector

16 cellular internalization, on human GBM cells. Therefore, this strategy could be used to improve

17 nanocarrier targeting efficiency to other type of cells in which the peptide can efficiently enter

18 i.e. brain neural stem cells. ${ }^{18,22,41}$

19 Previously, Paillard et al. reported that the internalization of untargeted LNCs was not

20 preferentially targeted into GBM cells and entered also healthy astrocytes. ${ }^{38}$ Additionally,

21 surface-functionalization with the fluoNFL peptide significantly enhanced the uptake of LNCs in

22 NHA, compared to control LNCs (LNC-DiA), NFL being a cell penetrating peptide. Therefore,

23 to investigate the targeting capacity of the LNC-fluoNFL2 towards U87MG cells, LNC-DiA and 
1 LNC-DiA-fluoNFL2 were incubated with NHA and their cellular uptake after $1 \mathrm{~h}$ and $6 \mathrm{~h}$ was

2 measured and compared with their uptake in U87MG cells (Fig. 9). At $1 \mathrm{~h}$, no significant

3 difference was observed between LNC-fluoNFL2 internalization in NHA and U87MG cells.

4 However, the rate of LNC-fluoNFL2 internalization was much faster in the GBM cells and the

5 nanovector entered significantly more in the cancer cells compared to NHA. Therefore, the

6 cellular internalization of LNC-fluoNFL2 was preferentially targeted towards the human GBM

7 cells compared to healthy cells.

8 To investigate the possible pathway(s) of LNC-fluoNFL2 internalization in U87MG cells, its

9 uptake was followed in different energetic conditions and in presence of various endocytosis

10 pathway inhibitors. The internalization of the nanocarrier was significantly reduced (compared to

$\left.1137{ }^{\circ} \mathrm{C}\right)$ when incubated at different energetic conditions $\left(4{ }^{\circ} \mathrm{C}\right.$ and ATP-depleted condition) (Fig.

12 10a). In ATP-depleted conditions, no LNC-DiA-fluoNFL2 uptake was showed after $1 \mathrm{~h}$, but an

13 increase to about $25 \%$ of the n.c after $6 \mathrm{~h}$ was observed. On the contrary, at $4{ }^{\circ} \mathrm{C}$, no LNC-DIA-

14 fluoNFL2 was internalized after $1 \mathrm{~h}$ and $6 \mathrm{~h}$ of incubation. This result could suggest that in ATP-

15 depleted conditions, after $6 \mathrm{~h}$, these nano-objects were able to be internalized via an independent-

16 energy pathway. But the same result was surprisingly not observed at $4^{\circ} \mathrm{C}$. Indeed, a higher

17 rigidity and a lower permeability of lipid bilayer have been demonstrated at low temperature and 18 could explain this difference ${ }^{42}$.

19 Thus, the LNC-fluoNFL2 uptake in U87MG cell was an energy-dependent active process.

20 Comparable trend was observed in cellular uptake of the fluoNFL alone (Fig. 10b) which was 21 also mentioned in previously reports. ${ }^{18}$

22 The dependency of cellular uptake on energy indicates that the internalization possibly occurs

23 by endocytosis. To further illustrate about the particular internalization pathway(s) involved, the 
1 cells were pretreated with various inhibitors of the chief endocytosis pathways. Treatment with

$2 \mathrm{M} \beta \mathrm{CD}$ depletes cholesterol and inhibits both clathrin- and caveolin-mediated endocytosis, DAM

3 prevents macropinocytosis, chlorpromazine blocks clathrin-dependent endocytosis and PMA

4 impedes caveolin-dependent endocytosis. ${ }^{38,43}$ As previously reported for the NFL peptide ${ }^{23}$

5 (also observed in our experiments, Fig. 11b), the internalization of the LNC-fluoNFL2 was not

6 dependent on one particular endocytosis pathway, rather on several and its uptake was

7 significantly reduced when cells were pretreated with these inhibitors (Fig. 11a). Taken together,

8 the predominant pathways involved in NFL-functionalized LNC internalization were

9 macropinocytosis, clathrin-dependent and caveolin-dependent endocytosis; similar to the free

10 peptide solution. However, the very low uptake of the non-functionalized LNC into U87MG

11 cells up to $6 \mathrm{~h}$ was not suitable to be used as control for evaluating its cellular uptake

12 mechanisms. Moreover, the $24 \mathrm{~h}$ time point has been tried for determining the possible LNC

13 internalization pathways. But the cells did not survive up to $24 \mathrm{~h}$ in presence of the different

14 endocytosis inhibitors and the mechanism of LNC uptake in U87MG cells could not be

15 determined by this method.

16 A promising ferrocifen-type anticancer drug FcTriOH was encapsulated in the LNCs. FcTriOH

17 belongs to the hydroxypropyl series of the acyclic ferrocifen family, possibly forms an

18 intrinsically electrophilic and cytotoxic metabolite i.e. tetrahydrofuran substituted quinone

19 methides in living cancer cells, and have shown significantly enhanced activity on hormone-

20 independent breast cancer cells compared to the acyclic ferrociphenol. ${ }^{12}$ This was the first time

21 this compound was studied in vivo on a human GBM tumor model in mice. The in vitro

22 antiproliferative activity of FcTriOH was assessed by MTS assay. The cells were treated with

$23 \quad 0.1-100 \mu \mathrm{M}$ of FcTriOH and its formulations for $72 \mathrm{~h}$. Up to $0.1 \mu \mathrm{M}$, cell survival was above 80 
$1 \%$ for all treatment groups (Fig. 12). Between $0.1-10 \mu \mathrm{M}$, the cell survival percentage drastically

2 reduced for cells treated with FcTriOH, LNC-FcTriOH and LNC-FcTriOH-fluoNFL2 resulting

3 in $\mathrm{IC}_{50}$ values of $1.31 \mu \mathrm{M}, 1.05 \mu \mathrm{M}$ and $0.46 \mu \mathrm{M}$ respectively. The survival of the cells treated

4 with control LNC reduced significantly between 10 and $100 \mu \mathrm{M}$ with an $\mathrm{IC}_{50}$ of $22.5 \mu \mathrm{M}$.

5 Corresponding concentrations of fluoNFL solution did not alter cell viability which was also

6 reported previously. ${ }^{18}$

7 In the preliminary in vivo study, an U87MG subcutaneous GBM tumor model was used to 8 evaluate potential tumor reduction efficacy or possible toxicity after two tail vein injections 9 equivalent to $20 \mathrm{mg} / \mathrm{kg} \mathrm{FcTriOH}$. As no previous reports about this FcTriOH administration in 10 animals were available, the dose was chosen based on previous in vivo studies involving other 11 ferrocifen molecules. ${ }^{44}$ The two i.v. injections were given on day 7 and day 10 . A tendency of 12 relative tumor volume gradual reduction was observed since the beginning of the treatment with 13 FcTriOH-loaded LNCs. A significant difference i.e. $40.1 \%$ and $44.2 \%$ lower relative tumor 14 volume for LNC-FcTriOH and FcTriOH-fluoNFL2 respectively, compared to the saline treated 15 group, was observed on by day 17 (Fig. 13) which was maintained up to day 22. The mouse 16 showed no behavioral signs of pain or irritation immediately after the injection. Additionally, the 17 weight of the mice never reduced and signs of pain and distress were not observed throughout 18 the study. However, the tumor reduction effect of the FcTriOH treatments was not observed from 19 day 24 (two weeks after the last injection). The tumor rapidly grew back and no significant 20 difference in relative tumor volume was observed. This possibly occurs as the drug is eliminated 21 resulting its antiproliferative effect to fade and the tumor to grow back. In fact, several

22 preclinical studies have used much higher number (6 to 20) of i.v. injections ${ }^{44-45}$ and observed a 23 significant difference on tumor growth. In clinical practice, chemotherapy is generally 
1 administered in several cycles; a treatment period followed by a waiting period for the patient to

2 wash-out and recover from the side effect of the drug. The cycle frequencies are optimized

3 depending on the treatment used. In future studies, the number of injections and/or dose should

4 be increased to possibly achieve tumor regression after FcTriOH-loaded LNC treatment.

5 Although the relative tumor volume of LNC-FcTriOH treated and LNC-FcTriOH-fluoNFL2

6 treated groups on day 17 was significantly lower from saline treated groups, the difference

7 among themselves were not significant. However, the average value of relative tumor growth

8 was slightly lower for NFL-functionalized LNC treated groups. The tendency may be more

9 clearly observed if more injections are given in the future studies.

10 The NFL-peptide concentration of LNC surface can be further increased for additional

11 enhancement of its internalization in human GBM cells. However, the currently used preparation

12 technique is not suitable for this purpose as precipitates were observed in fluoNFL peptide

13 solutions above $3 \mathrm{mM}$, probably due to its aqueous solubility limit. Additionally, covalent

14 coupling of NFL at the distal end of long-chain PEG has been described to hamper its GBM-

15 targeting properties. ${ }^{19}$ However, addition of NFL solution/suspension above $3 \mathrm{mM}$ in LNC

16 dispersions resulted a viscous and hydrogel like formulation (data not shown), which could be 17 interesting for local application in the cavity after surgical removal of the tumor. ${ }^{46}$

\section{EXPERIMENTAL}

\section{$20 \quad$ Materials}

21 Macrogol 15 hydroxystearate (Kolliphor ${ }^{\circledR}$ HS15) was purchased from BASF (Germany).

22 Hydrogenated phosphatidylcholine from soybean (Lipoid S PC-3) was provided from Lipoid

$23 \mathrm{GmbH}$ (Germany), caprylic/capric triglycerides (Labrafac Lipophile WL1349) was supplied by 
1 Gattefosse (France). FcTriOH was provided by PSL Chimie ParisTech (France), Feroscan SME.

2 5,6-Carboxyfluorescein labelled NFL.TBS-40.63 peptide (fluoNFL) was purchased from

3 Polypeptide Laboratories (France).

4 The human glioblastoma cell line U87MG was collected from ATCC (USA). Normal human

5 astrocytes (NHA), astrocyte basal medium (ABM), SingleQuots ${ }^{\mathrm{TM}}$ kit supplements \& growth

6 factors, L-glutamine, penicillin-streptomycin and Dulbecco's modified Eagle's medium with 1

7 g/L L-glucose (DMEM) were provided by Lonza (France). Methyl- $\beta$-cyclodextrin (M $\beta C D), 5-$

8 (N,N-dimethyl) amiloride hydrochloride (DAM), chlorpromazine (CP), phalloidin-

9 tetramethylrhodamine-B-isothiocyanate (phalloidin-TRITC), sodium azide and 2-deoxy-D-

10 glucose were purchased from Sigma (Germany). Phorbol-12-myristate-13-acetate (PMA) was

11 collected from Abcam (France). 4-(4-(dihexadecylamino)styryl)-N-methylpyridinium iodide)

12 (DiA), 4',6-diamidino-2-phenylindole (DAPI), Trypsin-EDTA 1x, non-essential amino acids

13 solution 100x (NEAA), fetal bovine serum (FBS) and ProLong Gold antifade were collected

14 from Thermo Fisher Scientific (USA). 3-carboxymethoxyphenyl-2-(4-sulfophrenyl)-2H-

15 tetrazolium (MTS) and phenazine methosulfate (PMS) was purchased from Promega (USA).

16 Normal human serum (NHS) was provided by the "Etablissement Français du Sang" (Angers,

17 France). Sheep erythrocytes and hemolysin were purchased from Eurobio (France). Sodium

18 chloride $(\mathrm{NaCl})$ was purchased from Prolabo (Fontenay-sous-bois, France). Ultra-pure water

19 (UPW) was obtained from a Millipore filtration system. All the other reagents and chemicals 20 were of analytical grade.

22 Preparation of lipid nanocapsules

23 Preparation of stock lipid nanocapsules 
1 Stock LNC (LNC-stock) was prepared using phase inversion temperature technique. ${ }^{21}$ In brief,

2 Kolliphor ${ }^{\circledR} \operatorname{HS} 15\left(16.9 \%\right.$ w/w), Lipoid ${ }^{\circledR}$ S PC-3 (1.5\% w/w), Labrafac Lipophile WL1349

$3(20.6 \% \mathrm{w} / \mathrm{w}), \mathrm{NaCl}(1.8 \% \mathrm{w} / \mathrm{w})$ and $\mathrm{UPW}(59.2 \% \mathrm{w} / \mathrm{w})$ were mixed under magnetic stirring at

$4 \quad 60{ }^{\circ} \mathrm{C}$ for $15 \mathrm{~min}$. Three heating-cooling cycles were performed between $90{ }^{\circ} \mathrm{C}$ and $60{ }^{\circ} \mathrm{C}$.

5 During the last cooling step, when the temperature was in the phase inversion zone $\left(78-83{ }^{\circ} \mathrm{C}\right)$,

6 ice-cold UPW was added (final concentration $88.4 \% \mathrm{w} / \mathrm{w}$ ) to induce irreversible shock and form

7 the LNC-stock. The nanocapsules were then passed through $0.2 \mu \mathrm{m}$ cellulose acetate filter to 8 remove any aggregates and stored at $4{ }^{\circ} \mathrm{C}$.

9 DiA-labelled stock LNC was prepared by incorporating $0.1 \%(w / w) ~ D i A$ in the formulation at 10 the first step with other excipients.

12 Preparation of fluoNFL functionalized lipid nanocapsules and lipid nanocapsules

$131 \mathrm{~mL}$ of stock LNC (LNC-stock) was stirred at room temperature for $24 \mathrm{~h}$ with $0.369 \mathrm{~mL}$ of 1 $14 \mathrm{mM}(0.86 \% \mathrm{w} / \mathrm{w})$ (similar to $\left.{ }^{19,22}\right)$ or $3 \mathrm{mM}(2.57 \% \mathrm{w} / \mathrm{w})$ fluoNFL solution (in water) to 15 prepare the fluoNFL functionalized LNCs (LNC-fluoNFL1 and LNC-fluoNFL2 respectively).

16 Similarly, $1 \mathrm{~mL}$ of the $\mathrm{LNC}$ stock was stirred at room temperature for $24 \mathrm{~h}$ with $0.369 \mathrm{~mL}$ of 17 UPW to produce final control LNCs.

18 The DiA $(0.1 \% \mathrm{w} / \mathrm{w})$ labelled LNCs was also functionalized with the fluoNFL by same 19 method as LNC-fluoNFL1 and LNC-fluoNFL2.

\section{Preparation of FcTriOH-loaded lipid nanocapsules}

22 The FcTriOH-loaded LNC (LNC-FcTriOH) was prepared similarly as control LNCs, except 23 FcTriOH $(0.9 \% \mathrm{w} / \mathrm{w})$ was added at the first step of the formulation with the other excipients. 
1 Subsequently, fluoNFL was adsorbed at their surface using identical method as LNC-fluoNFL2

2 to produce drug loaded NFL-functionalized LNCs.

$4 \quad$ Optimization of lipid nanocapsules for in vivo studies

5 For in vivo studies, the amount of ice-cold UPW used to induce shock to produce the LNCs

6 was adjusted (final concentration $70.9 \% \mathrm{w} / \mathrm{w}$ ) to produce concentrated $\mathrm{LNCs}$ according to

7 previously published article. ${ }^{24} \mathrm{NaCl}$ concentration was also adjusted to keep the final

8 formulations isotonic with blood.

10 Characterization of the lipid nanocapsules

11 Dynamic light scattering, laser-Doppler electrophoresis and nanoparticle tracking analysis

12 The mean diameter and polydispersity index (PDI) of the LNCs were determined by dynamic

13 light scattering (DLS) technique using Zetasizer Nano ZS (Malvern Instruments Ltd, UK). The

14 LNCs were diluted 100 -folds in UPW before the analysis. The measurements were performed at

15 backscatter angle of $173^{\circ}$. The measured average values were calculated from 3 runs, with 10

16 measurements within each run.

17 Zeta potential of the nanocarriers was measured using laser Doppler micro-electrophoresis 18 using Zetasizer Nano ZS (Malvern Instruments Ltd, UK).

19 Additionally, the particle concentration in the control LNC dispersion was determined using

20 nanoparticle tracking analysis (NTA) as described previously. ${ }^{37}$ The NTA was carried out using

21 the NanoSight NS300 (Malvern Instruments Ltd, UK). Briefly, the NDDS samples were diluted

22 to optimum concentrations with UPW and were infused in the sample chamber using a syringe

23 pump at $30 \mu \mathrm{L} / \mathrm{min}$ rate. A $405 \mathrm{~nm}$ laser was used to illuminate the particles, and their Brownian 
1 motion was recorded into three $60 \mathrm{~s}$ videos $(25 \mathrm{fps})$ using the sCMOS type camera of the

2 instrument. Subsequently, the NTA software (NTA 3.2 Dev Build 3.2.16) analyzed the

3 recordings, tracked the motion of the particles and calculated the number of particles in the

4 samples. The experiment was performed in triplicate.

$6 \quad$ High-performance liquid chromatography

7 The peptide concentration was indirectly measured by quantifying the free peptide present in 8 the formulations using a supplier recommended HPLC method. Briefly, the fluoNFL 9 functionalized LNCs were filtered by centrifugation at $4000 \mathrm{~g}$ for 30 min using Amicon Ultra$100.5 \mathrm{~mL}$ centrifugal filters having molecular weight cut off (MWCO) $100 \mathrm{kD}$ (Millipore). The 11 filtrate containing the free fluoNFL was collected and the peptide dosage was performed in a 12 HPLC system (Waters, France). A C18 analytical column ( 250 x $4.6 \mathrm{~mm}, 5 \mu \mathrm{m}$, Waters, France) 13 was used at room temperature. $0.1 \%$ TFA in UPW and $0.1 \%$ TFA in acetonitrile were used as 14 mobile phases (gradient: 80:20 $\rightarrow$ 55:25, $25 \mathrm{~min}$ ). Flow rate was $1 \mathrm{~mL} / \mathrm{min}$, injection volume

15 was $10 \mu \mathrm{L}$ and fluoNFL was quantified by an UV detector at $\lambda$ of $220 \mathrm{~nm}$. Analysis of the data 16 was performed by Empower 3 software (Waters). Retention time was of 18 min. Calibration 17 curves were established by quantifying the area under the curves (AUCs) of $1-100 \mu \mathrm{g} / \mathrm{mL}$ 18 solutions of fluoNFL in UPW. The peptide solution and LNCs alone were also filtered and 19 quantified as positive and negative controls.

20 To quantify total (encapsulated and unencapsulated) drug concentration, LNCs were broken by 21 mixing vigorously with an appropriate volume of ethanol (40 folds for LNCs prepared for in 22 vitro experiments, 100-folds for concentrated LNCs prepared for in vivo) to keep dissolved drug 23 concentration between $5-75 \mu \mathrm{g} / \mathrm{mL}$. To quantify unencapsulated drug concentration, 
1 formulations were placed on centrifugal concentrator devices with polyethersulfone membrane

2 (MWCO $30 \mathrm{kD}$, Amicon Ultra-500, Millipore) and centrifuged at $4000 \mathrm{~g}$ for 30 minutes to

3 separate the free drug from the rest of the formulation. The filtrates containing unencapsulated

4 drug were collected and ethanol (2-folds) was added to solubilize any undissolved drug. Drug

5 dosage in the above-mentioned samples was performed in a HPLC system (Waters, France). A

6 C18 analytical column $(250 \times 4.6 \mathrm{~mm}, 5 \mu \mathrm{m}$, Waters, France $)$ was used at room temperature.

7 UPW and acetonitrile (45:55, v/v) were used as mobile phases. Flow rate was $1 \mathrm{~mL} / \mathrm{min}$,

8 injection volume was $10 \mu \mathrm{L}$ and $\mathrm{FcTriOH}$ was detected at $304 \mathrm{~nm}$. Analysis of the data was

9 performed by Empower 3 software (Waters). Retention time of FcTriOH was $8.1 \mathrm{~min}$.

10 Encapsulation efficiency, EE (\%) was calculated using the following equation:

$\mathrm{EE}(\%)=\frac{(\text { Total drug conc. in LNC }- \text { unencapsulated drug conc. in LNC) } \times 100}{\text { Initial drug conc. in LNC }}$

11 Drug loading was calculated using the following equation:

Drug loading $(\% \mathrm{w} / \mathrm{w})=\frac{\text { Mass of encapsulated drug in } 1 \mathrm{~mL} \mathrm{LNC} \mathrm{dispersion} \times 100}{\text { Total mass of excipients in } 1 \mathrm{~mL} \mathrm{LNC} \mathrm{dispersion}}$

13 Interaction between $L N C s$ and fluoNFL

14 The LNC-fluoNFL2 and control LNCs were diluted in UPW or in various concentrations

$15(0.005,0.05,0.15,0.25,0.5$ and $1 \mathrm{M})$ of $\mathrm{NaCl}$ or Tris buffer, incubated for 30 minutes before

16 measuring their size by DLS. ${ }^{22}$

17 Additionally, LNC-fluoNFL2 and control fluoNFL solutions were taken in dialysis bags

18 (MWCO $100 \mathrm{kD}$, Spectra/Por ${ }^{\circledR}$ biotech grade cellulose ester membrane, SpectrumLabs,

19 Netherlands) and dialyzed against Tris buffer $(0.05 \mathrm{M}, \mathrm{pH} 7.4)$ at $37^{\circ} \mathrm{C}$, stirred at $75 \mathrm{rpm}$. At

20 various time points $(0.25,0.5,0.75,1,2,3,4,6$ and $24 \mathrm{~h})$ samples were collected from the 
1 receiver chamber and amount of the free peptide was quantified using the HPLC method

2 mentioned above.

4 Complement consumption assay (CH50 assay)

5 The residual hemolytic capacity of NHS towards antibody-sensitized sheep erythrocytes after

6 incubation with different LNC formulations was measured to evaluate the complement activation

7 by the formulations. ${ }^{47}$ In brief, ${ }^{37}$ aliquots of NHS were incubated with increasing concentrations

8 of the LNCs at $37{ }^{\circ} \mathrm{C}$ for $1 \mathrm{~h}$. Subsequently, the different volumes of the NHS were incubated

9 with a fixed volume of hemolysin-sensitized sheep erythrocytes at $37^{\circ} \mathrm{C}$ for $45 \mathrm{~min}$. The volume

10 of serum that can lyse $50 \%$ of the erythrocytes was calculated ("CH50 units") for each sample

11 and percentage of $\mathrm{CH} 50$ unit consumption relative to negative control was determined as

12 described previously. ${ }^{34}$ Particle number in the LNC dispersion was determined by NTA and

13 nanocarrier concentration per $\mathrm{mL}$ of NHS was calculated according to following equation:

Particle number per mL of NHS $=$ Particle conc. in NDDS dispersion $\times \frac{\text { vol. of NDDS added }}{\text { vol. of NHS }}$

14 Subsequently, surface area of the NDDSs per mL of NHS was calculated according to the

15 following equation:

Surface area $=$ Particle number per $\mathrm{mL}$ of NHS $\times \pi \times(\text { average particle diameter })^{2}$

16 The CH50 unit consumption by the different LNCs was compared by plotting the percentage

17 of $\mathrm{CH} 50$ unit consumption as a function of their surface area.

\section{Cell culture}

20 The human glioblastoma cell line U87MG was cultured at $37{ }^{\circ} \mathrm{C}$ under $5 \% \mathrm{CO}_{2}$ in DMEM 21 supplemented with $10 \%$ FBS, 5\% L-glutamine, $5 \%$ NEAA and $5 \%$ penicillin-streptomycin. 
1 NHA was cultured at $37{ }^{\circ} \mathrm{C}$ under $5 \% \mathrm{CO}_{2}$ in ABM supplemented by the 'AGM SingleQuot ${ }^{\mathrm{TM}}$

2 Kit'. The cells were passaged once they were about $70 \%$ confluence.

$4 \quad$ Flow cytometry

$5 \quad$ Kinetics of LNC internalization in U87MG cells

6 The kinetics of internalization of the DiA-labelled LNCs (LNC-DiA, LNC-DiA-fluoNFL1 and 7 LNC-DiA-fluoNFL2) in U87MG cells was assessed using the BD FACSCanto ${ }^{\mathrm{TM}}$ II flow 8 cytometer (BD Biosciences). In brief, cells were seeded in 6-well plates at $5 \times 10^{5}$ cells/well 9 concentration for 24 hours. Subsequently, they were treated with the different DiA-labelled 10 LNCs $(1.23 \mathrm{mg} / \mathrm{mL})$ for $0.5,1,6$ and $24 \mathrm{~h}$. Afterwards, the cells were washed three times with 11 ice-cold phosphate buffer saline 1x (PBS), detached by incubating 5-10 minutes with Trypsin12 EDTA 1x. The cells were then centrifuged at $2000 \mathrm{rpm}$ for 5 minutes, the supernatant was 13 aspirated and the cell pellet was re-dispersed in PBS. The centrifugation and re-dispersion cycle 14 was repeated twice more. Finally, the cells were suspended in trypan blue (final trypan blue 15 concentration $0.12 \% \mathrm{w} / \mathrm{v}$ ) and the percentage of DiA positive $\left(\mathrm{DiA}^{+\mathrm{ve}}\right.$ ) or FAM positive $16\left(\mathrm{FAM}^{+\mathrm{ve}}\right)$ cells were analyzed by the flow cytometer. Each experiment was performed in 17 triplicate and 20,000 events per sample were analyzed in each experiment.

19 Targeting-capability of fluoNFL-functionalized LNCs towards GBM cells compared to healthy 20 cells

21 To assess the targeting-capability of the fluoNFL-functionalized LNC towards GBM cells 22 compared to healthy cells, NHA was treated for $1 \mathrm{~h}$ and $6 \mathrm{~h}$ with LNC-DiA-fluoNFL2 (method 
1 mentioned above) at $37{ }^{\circ} \mathrm{C}$ and percentage of $\mathrm{DiA}^{+\mathrm{ve}}$ cells was measured using the above-

2 mentioned method, and compared with the results of U87MG cells.

$4 \quad$ Mechanism of fluoNFL-functionalized LNCs internalization in U87MG cells

5 To evaluate the dependency of NFL-functionalized LNC cellular internalization on energy, 6 U87MG cells were pre-incubated for $30 \mathrm{~min}$ at $4{ }^{\circ} \mathrm{C}$ or pretreated for 30 minutes at $37{ }^{\circ} \mathrm{C}\left(\mathrm{NaN}_{3}\right.$

$7 \quad 10 \mathrm{mM}$ and 2-deoxy-D-glucose $6 \mathrm{mM}$ ) to deplete cellular ATP ${ }^{23}$. Subsequently, the cells were

8 treated for 1 and $6 \mathrm{~h}$ with the LNC-DiA-fluoNFL2 and percentage of DiA ${ }^{+v e}$ cells were measured 9 by the above-mentioned method.

10 To investigate the possible pathways of LNC-DiA-fluoNFL2 internalization in U87MG, cells 11 were pretreated with different inhibitors (MBCD $10 \mathrm{mg} / \mathrm{mL}$, DAM $1 \mathrm{mM}, \mathrm{CP} 50 \mu \mathrm{M}$ and PMA

$1210 \mu \mathrm{g} / \mathrm{mL}$ ) for $30 \mathrm{~min}$ at $37{ }^{\circ} \mathrm{C}^{23}$ followed by $1 \mathrm{~h}$ treatment with the nanocarrier and percentage 13 of $\mathrm{DiA}^{+\mathrm{ve}}$ was quantified.

14 In all the above-mentioned conditions $\left(37^{\circ} \mathrm{C}\right.$, pre-incubation at $4{ }^{\circ} \mathrm{C}$, pre-treatment for ATP 15 depletion, and pre-treatment with various inhibitors), internalization of fluoNFL (at equivalent 16 concentration of LNC-DiA-fluoNFL2) in U87MG cells was assessed by measuring FAM ${ }^{+v e}$ cells 17 to assess if the fluoNFL by itself regulates the internalization of NFL-functionalized LNC.

\section{Confocal microscopy}

20 To visualize the potential effects of the fluoNFL peptide on LNC internalization, U87MG cells 21 were seeded $\left(3 \times 10^{4}\right.$ cells $/$ well $)$ in 24 well plates containing coverslips and incubated at $37{ }^{\circ} \mathrm{C}$

22 for $72 \mathrm{~h}$ (medium was carefully replaced every $24 \mathrm{~h}$ ) to allow the cells to grow on the coverslips.

23 Subsequently, the cells were treated with $1.23 \mathrm{mg} / \mathrm{mL}$ of LNC-DiA or LNC-DiA-fluoNFL2 for 1 
$1 \mathrm{~h}$ and $6 \mathrm{~h}$ at $37{ }^{\circ} \mathrm{C}$. Afterwards, the cells were washed three times with PBS and fixed with $4 \%$

2 paraformaldehyde for $20 \mathrm{~min}$ at room temperature. Then, the cells were washed twice with PBS

3 and permeabilized by incubation with $0.1 \%$ Triton X-100 for $10 \mathrm{~min}$. The cells were washed

4 twice with PBS and incubated with $0.7 \mu \mathrm{M}$ of phalloidin-TRITC for $1 \mathrm{~h}$ at room temperature.

5 Subsequently, the cells were washed twice with PBS and incubated with $3 \mu \mathrm{M}$ DAPI for 10

6 minutes. Finally, the cells were washed 3-times with PBS and the coverslips were mounted using

7 ProLong Gold antifade mounting medium. The cells were then visualized and images were

8 captured by a confocal microscope (LSM 700 Zeiss). DAPI was excited with a $405 \mathrm{~nm}$

9 wavelength and recorded at 409-453 nm (blue channel), DiA and fluoNFL were excited with a

$10458 \mathrm{~nm}$ wavelength and recorded at 558-666 nm (green channel) whereas TRITC was excited

11 with a $561 \mathrm{~nm}$ wavelength and recorded at $564-632 \mathrm{~nm}$ (red channel).

\section{In vitro efficacy}

14 Viability of the U87MG cells to various LNC treatments was assessed by MTS assay. ${ }^{19}$ In

15 brief, the U87MG cells were seeded in 96 well plates (5000 cells/well) and incubated for $24 \mathrm{~h}$.

16 Then the medium was replaced with various concentrations of LNCs $(60-600,000$ folds diluted in

17 DMEM) (LNC-blank, LNC-FcTriOH and LNC-FcTriOH-fluoNFL2), FcTriOH (22-220,000

18 folds dilution in DMEM) and fluoNFL (125-4,983,383 folds dilution in DMEM) and treated for

1972 hours at $37^{\circ} \mathrm{C}$. After that, each well content was replaced with $100 \mu \mathrm{L}$ of fresh DMEM.

20 Additionally, $20 \mu \mathrm{L}$ of MTS-PMS (20:1) mixture was added in each well and incubated at $37{ }^{\circ} \mathrm{C}$

21 for $2 \mathrm{~h}$. Absorbance of the samples at $490 \mathrm{~nm}$ was recorded using a microplate reader

22 (SpectraMax M2, Molecular Devices). The absorbance of the cells incubated with only DMEM 
1 was considered as $100 \%$ of cell survival $\left(\mathrm{Abs}^{+v e}\right)$, and the cells treated by $0.5 \%$ Triton X-100

2 was considered as $0 \%\left(\mathrm{Abs}^{-\mathrm{ve}}\right)$. Cell survival was calculated using the following equation:

3 Cell survival $(\%)=\left[\left(\mathrm{Abs}^{\text {sample }}-\mathrm{Abs}^{-\mathrm{ve}}\right) \div\left(\mathrm{Abs}^{+\mathrm{ve}}-\mathrm{Abs}^{-\mathrm{ve}}\right)\right] \times 100$

4

$5 \quad$ Preliminary in vivo study in ectopic xenograft model

6 The preliminary in vivo study was performed following the guidelines of the European

7 regulations. The experimental protocol was approved by the 'French Ministry of National

8 Education, Higher Education and Research': APAFIS\#8293-2017032217458665v3. Seven

9 weeks old female NMRI nude mice were collected from Janvier Labs (France). The animals

10 were kept in the animal facility for one week for acclimatization and were given sufficient food

11 and water throughout the study.

12 After acclimatization period, the animals were anesthetized by temporary exposure to $2 \%$

13 isoflurane in oxygen to induce anesthesia followed by $1.5 \%$ isoflurane in oxygen delivered by

14 face mask to maintain it. The U87MG cells were trypsinized and washed three times before

15 injected subcutaneously in the right flank of the mice $\left(2 \times 10^{6}\right.$ cells in $50 \mu \mathrm{L}$ PBS $)$. When the

16 tumor became palpable, tumor volume was measured using an electronic caliper using the

17 following equation: Volume $=\pi / 6 \times$ length $\times$ width $^{2}$. Seven days after cell injection, the mice

18 were divided into 5 groups to have similar average tumor volume. The animals were anesthetized

19 (by above mentioned method) and received the following treatments by injections in the tail vein

20 on day 7 and day 10- Group 1: $70 \mu \mathrm{L}$ Saline $(\mathrm{n}=7)$; Group 2: $70 \mu \mathrm{L}$ of LNC-blank equivalent to

$21822.4 \mathrm{mg}$ LNC per $\mathrm{kg}$ of body weight $(\mathrm{n}=8)$; Group 3: $70 \mu \mathrm{L}$ of LNC-blank-fluoNFL2

22 equivalent to $822.4 \mathrm{mg} \mathrm{LNC}$ and $21.5 \mathrm{mg}$ peptide per $\mathrm{kg}$ of body weight $(\mathrm{n}=8)$, Group 4: $70 \mu \mathrm{L}$

23 of LNC-FcTriOH equivalent to $20 \mathrm{mg}$ FcTriOH per $\mathrm{kg}$ of body weight (equivalent to $822.4 \mathrm{mg}$ 
1 LNC per kg of body weight) ( $\mathrm{n}=8)$; Group 5: $70 \mu \mathrm{L}$ of LNC-FcTriOH-fluoNFL2 equivalent to

$220 \mathrm{mg}$ FcTriOH per $\mathrm{kg}$ of body weight (equivalent to $822.4 \mathrm{mg} \mathrm{LNC}$ and $21.5 \mathrm{mg}$ peptide per $\mathrm{kg}$

3 of body weight) $(\mathrm{n}=8)$. The length and width of the tumor was followed regularly (every day in

4 the first week of treatment and then 3-times a week). Weight and behavior of the animals were 5 daily followed.

\section{$7 \quad$ Statistical analysis}

8 The experiments were performed at least 3 times. Results obtained from the experiments were 9 analyzed statistically using GraphPad Prism ${ }^{\circledR}$ software. Mean and standard deviation (SD) were 10 determined and values are represented as Mean $\pm \mathrm{SD}$. T-test or One way analysis of variance

11 (ANOVA) (with Tukey post-test to compare among individual groups, and Dunnett's post-test to 12 compare with control) was performed in the respective fields. P-value less than $0.05(\mathrm{p}<0.05)$

13 was considered to be statistically significant.

\section{CONCLUSIONS}

16 In this study, we have shown that surface-functionalization with NFL peptide can enhance the 17 uptake of LNCs in human GBM cells in a dose-dependent manner. Moreover, the peptide18 functionalized LNCs reached the cytoplasm at much higher concentration compared to the non-

19 functionalized control LNCs. Additionally, the peptide functionalized LNCs were preferentially 20 internalized into GBM cells compared to healthy human astrocytes showing the targeting 21 capacity of the nanovector. The internalization of this nanocarrier in the U87MG cells was 22 energy-dependent and occurred by a combination of macropinocytosis, clathrin-mediated and 23 caveolin-mediated endocytosis, similar pathway as the NFL peptide solution. Encapsulation for 
1 the first time of this FcTriOH in the GBM targeting LNCs resulted in a decreased $\mathrm{IC}_{50}$. The

2 preliminary in vivo study in an ectopic human GBM xenograft model showed that the drug-

3 loaded LNC therapy did not cause any pain or distress after i.v. administration and their tumor

4 reduction efficacy was promising. However, more cycles of chemotherapy seemed necessary in

5 future experiments to avail the benefit of functionalization. Moreover, further experiments on an

6 orthotopic xenograft mouse model, after i.v. injections, will be necessary to consider the main

7 biological barriers to be crossed to reach the target: BBB and BBTB ${ }^{48}$. Overall, enhancement of

8 NFL peptide concentration on LNC surface is a promising strategy for greater and targeted

9 nanocarrier internalization into human glioblastoma cells, and the FcTriOH-loaded LNCs are

10 promising therapy approach for glioblastoma.

\section{CONFLICTS OF INTEREST}

13 There are no conflicts to declare.

\section{ACKNOWLEDGEMENTS}

16 The authors would like to thank P. Legras (Service Commun d'Animalerie Hospitalo-

17 Universitaire, Angers, France) for his technical assistance in animal experiments, C. Guillet

18 (Plate-forme d'Analyse Cellulaire et Moléculaire, University of Angers) for her procedural

19 guidance in the FACS analyses, R. Perrot (Service Commun d'Imageries et d'Analyses

20 Microscopiques, University of Angers) for his support in confocal microscopy and the SME

21 Feroscan for its supply in ferrocifens. This work was funded by the NanoFar Consortium of the

22 Erasmus Mundus program and "fonds Léon Fredericq", CHU, University of Liege, Liege,

23 Belgium. The authors also thank 'La ligue contre le cancer 49' for their support in this work. 
Electronic Supplementary Information (ESI) available: Figures showing the results of MTS assays of blank LNCs and fluoNFL solutions. See DOI: 10.1039/x0xx00000x

\section{List of abbreviations}

BBB: blood-brain barrier; BBTB: blood-brain tumor barrier; CP: chlorpromazine; DAM: 5-

(N,N-dimethyl) amiloride hydrochloride; DiA: 4-(4-(dihexadecylamino)styryl)-Nmethylpyridinium iodide); DLS: dynamic light scattering; EE: Encapsulation efficiency; EPR: enhanced permeability and retention; FcTriOH: 4-ferrocenyl-5,5-bis(4-hydroxyphenyl)-pent-4-

10 en-1-ol; fluoNFL: FAM-labelled NFL-TBS.40-63 peptide; GBM: glioblastoma; HPLC: high

11 performance liquid chromatography; IC50: inhibitory concentration 50; LNC: lipid nanocapsule;

12 M 1 CD: Methyl- $\beta$-cyclodextrin; NDDS: nanosized-drug delivery system; NFL: neurofilament

13 light subunit derived 24 amino acid tubulin binding site peptide NFL-TBS.40-63; NHA: normal

14 human astrocytes; NHS: normal human serum; NTA, nanoparticle tracking analysis; PDI:

15 polydispersity index; phalloidin-TRITC: phalloidin-tetramethylrhodamine-B-isothiocyanate;

16 PMA: phorbol-12-myristate-13- acetate; UPW: ultra-pure water.

\section{REFERENCES}

19 1. Louis, D. N.; Perry, A.; Reifenberger, G.; von Deimling, A.; Figarella-Branger, D.; 20 Cavenee, W. K.; Ohgaki, H.; Wiestler, O. D.; Kleihues, P.; Ellison, D. W., The 2016 World 21 Health Organization Classification of Tumors of the Central Nervous System: A Summary. Acta 22 Neuropathol. 2016, 131, 803-20.

23 2. Stupp, R.; Hegi, M. E.; Mason, W. P.; van den Bent, M. J.; Taphoorn, M. J.; Janzer, R. 24 C.; Ludwin, S. K.; Allgeier, A.; Fisher, B.; Belanger, K.; Hau, P.; Brandes, A. A.; Gijtenbeek, J.; 25 Marosi, C.; Vecht, C. J.; Mokhtari, K.; Wesseling, P.; Villa, S.; Eisenhauer, E.; Gorlia, T.;

26 Weller, M.; Lacombe, D.; Cairncross, J. G.; Mirimanoff, R. O.; European Organisation for, R.; 27 Treatment of Cancer Brain, T.; Radiation Oncology, G.; National Cancer Institute of Canada 28 Clinical Trials, G., Effects of Radiotherapy with Concomitant and Adjuvant Temozolomide 
Versus Radiotherapy Alone on Survival in Glioblastoma in a Randomised Phase Iii Study: 5Year Analysis of the Eortc-Ncic Trial. Lancet Oncol. 2009, 10, 459-66.

3. Thomas, A. A.; Brennan, C. W.; DeAngelis, L. M.; Omuro, A. M., Emerging Therapies for Glioblastoma. JAMA neurology 2014, 71, 1437-44.

4. Netsky, M. G.; August, B.; Fowler, W., The Longevity of Patients with Glioblastoma Multiforme. J. Neurosurg. 1950, 7, 261-9.

5. $\quad$ Peer, D.; Karp, J. M.; Hong, S.; Farokhzad, O. C.; Margalit, R.; Langer, R., Nanocarriers as an Emerging Platform for Cancer Therapy. Nat. Nanotechnol. 2007, 2, 751-760.

6. Bernardi, A.; Braganhol, E.; Jager, E.; Figueiro, F.; Edelweiss, M. I.; Pohlmann, A. R.; Guterres, S. S.; Battastini, A. M., Indomethacin-Loaded Nanocapsules Treatment Reduces in Vivo Glioblastoma Growth in a Rat Glioma Model. Cancer Lett. 2009, 281, 53-63.

7. Huynh, N. T.; Passirani, C.; Saulnier, P.; Benoit, J. P., Lipid Nanocapsules: A New Platform for Nanomedicine. Int. J. Pharm. 2009, 379, 201-9.

8. Thomas, O.; Lagarce, F., Lipid Nanocapsules: A Nanocarrier Suitable for Scale-up Process. J. Drug Delivery Sci. Technol. 2013, 23, 555-559.

9. Allard, E.; Huynh, N. T.; Vessieres, A.; Pigeon, P.; Jaouen, G.; Benoit, J. P.; Passirani, C., Dose Effect Activity of Ferrocifen-Loaded Lipid Nanocapsules on a 91-Glioma Model. Int. J. Pharm. 2009, 379, 317-23.

10. Roger, M.; Clavreul, A.; Huynh, N. T.; Passirani, C.; Schiller, P.; Vessieres, A.; MonteroMenei, C.; Menei, P., Ferrociphenol Lipid Nanocapsule Delivery by Mesenchymal Stromal Cells in Brain Tumor Therapy. Int. J. Pharm. 2012, 423, 63-8.

11. Zanotto-Filho, A.; Coradini, K.; Braganhol, E.; Schroder, R.; de Oliveira, C. M.; SimoesPires, A.; Battastini, A. M.; Pohlmann, A. R.; Guterres, S. S.; Forcelini, C. M.; Beck, R. C.; Moreira, J. C., Curcumin-Loaded Lipid-Core Nanocapsules as a Strategy to Improve Pharmacological Efficacy of Curcumin in Glioma Treatment. Eur. J. Pharm. Biopharm. 2013, 83, 156-67.

12. Wang, Y.; Pigeon, P.; Top, S.; McGlinchey, M. J.; Jaouen, G., Organometallic Antitumor Compounds: Ferrocifens as Precursors to Quinone Methides. Angew. Chem. Int. Ed. Engl. 2015, 54, 10230-3.

13. Jaouen, G.; Pigeon, P.; Top, S. Metallocene Derivatives with Anticancer Activity. WO2015063201 (A1), 2015.

14. Yang, Y.; Yan, Z.; Wei, D.; Zhong, J.; Liu, L.; Zhang, L.; Wang, F.; Wei, X.; Xie, C.; Lu, W.; He, D., Tumor-Penetrating Peptide Functionalization Enhances the Anti-Glioblastoma Effect of Doxorubicin Liposomes. Nanotechnology 2013, 24, 405101.

15. Liu, G.; Shen, H.; Mao, J.; Zhang, L.; Jiang, Z.; Sun, T.; Lan, Q.; Zhang, Z., Transferrin Modified Graphene Oxide for Glioma-Targeted Drug Delivery: In Vitro and in Vivo Evaluations. ACS Appl Mater Interfaces 2013, 5, 6909-14.

16. Fu, Y.; An, N.; Li, K.; Zheng, Y.; Liang, A., Chlorotoxin-Conjugated Nanoparticles as Potential Glioma-Targeted Drugs. J. Neurooncol. 2012, 107, 457-62.

17. Wei, X.; Gao, J.; Zhan, C.; Xie, C.; Chai, Z.; Ran, D.; Ying, M.; Zheng, P.; Lu, W., Liposome-Based Glioma Targeted Drug Delivery Enabled by Stable Peptide Ligands. J. Control. Release 2015, 218, 13-21.

18. Berges, R.; Balzeau, J.; Peterson, A. C.; Eyer, J., A Tubulin Binding Peptide Targets Glioma Cells Disrupting Their Microtubules, Blocking Migration, and Inducing Apoptosis. Mol. Ther. 2012, 20, 1367-77. 
19. Balzeau, J.; Pinier, M.; Berges, R.; Saulnier, P.; Benoit, J. P.; Eyer, J., The Effect of Functionalizing Lipid Nanocapsules with Nfl-Tbs.40-63 Peptide on Their Uptake by Glioblastoma Cells. Biomaterials 2013, 34, 3381-9.

20. Laine, A. L.; Huynh, N. T.; Clavreul, A.; Balzeau, J.; Bejaud, J.; Vessieres, A.; Benoit, J. P.; Eyer, J.; Passirani, C., Brain Tumour Targeting Strategies Via Coated Ferrociphenol Lipid Nanocapsules. Eur. J. Pharm. Biopharm. 2012, 81, 690-3.

21. Heurtault, B.; Saulnier, P.; Pech, B.; Proust, J. E.; Benoit, J. P., A Novel Phase InversionBased Process for the Preparation of Lipid Nanocarriers. Pharm. Res. 2002, 19, 875-80.

22. Carradori, D.; Saulnier, P.; Preat, V.; des Rieux, A.; Eyer, J., Nfl-Lipid Nanocapsules for Brain Neural Stem Cell Targeting in Vitro and in Vivo. J. Control. Release 2016, 238, $253-62$.

23. Lepinoux-Chambaud, C.; Eyer, J., The Nfl-Tbs.40-63 Anti-Glioblastoma Peptide Enters Selectively in Glioma Cells by Endocytosis. Int. J. Pharm. 2013, 454, 738-47.

24. Huynh, N. T.; Passirani, C.; Allard-Vannier, E.; Lemaire, L.; Roux, J.; Garcion, E.; Vessieres, A.; Benoit, J. P., Administration-Dependent Efficacy of Ferrociphenol Lipid Nanocapsules for the Treatment of Intracranial 91 Rat Gliosarcoma. Int. J. Pharm. 2012, 423, 5562.

25. Allard, E.; Jarnet, D.; Vessieres, A.; Vinchon-Petit, S.; Jaouen, G.; Benoit, J. P.; Passirani, C., Local Delivery of Ferrociphenol Lipid Nanocapsules Followed by External Radiotherapy as a Synergistic Treatment against Intracranial 91 Glioma Xenograft. Pharm. Res. 2010, 27, 56-64.

26. Haar, C. P.; Hebbar, P.; Wallace, G. C. t.; Das, A.; Vandergrift, W. A., 3rd; Smith, J. A.; Giglio, P.; Patel, S. J.; Ray, S. K.; Banik, N. L., Drug Resistance in Glioblastoma: A Mini Review. Neurochem. Res. 2012, 37, 1192-200.

27. Straubinger, R. M.; Sharma, A.; Murray, M.; Mayhew, E., Novel Taxol Formulations: Taxol-Containing Liposomes. J. Natl. Cancer Inst. 1993, 69-78.

28. Berges, R.; Balzeau, J.; Takahashi, M.; Prevost, C.; Eyer, J., Structure-Function Analysis of the Glioma Targeting Nfl-Tbs.40-63 Peptide Corresponding to the Tubulin-Binding Site on the Light Neurofilament Subunit. PLoS One 2012, 7, e49436.

29. Allard, E.; Passirani, C.; Benoit, J. P., Convection-Enhanced Delivery of Nanocarriers for the Treatment of Brain Tumors. Biomaterials 2009, 30, 2302-18.

30. Torchilin, V. P.; Rammohan, R.; Weissig, V.; Levchenko, T. S., Tat Peptide on the Surface of Liposomes Affords Their Efficient Intracellular Delivery Even at Low Temperature and in the Presence of Metabolic Inhibitors. P. Natl. Acad. Sci. USA 2001, 98, 8786-8791. 31. Yu, X.; Zheng, J., Polymorphic Structures of Alzheimer's Beta-Amyloid Globulomers. PLoS One 2011, 6, e20575.

32. Zhou, M.; Smith, A. M.; Das, A. K.; Hodson, N. W.; Collins, R. F.; Ulijn, R. V.; Gough, J. E., Self-Assembled Peptide-Based Hydrogels as Scaffolds for Anchorage-Dependent Cells. Biomaterials 2009, 30, 2523-30.

33. Larsen, T. H.; Branco, M. C.; Rajagopal, K.; Schneider, J. P.; Furst, E. M., SequenceDependent Gelation Kinetics of B-Hairpin Peptide Hydrogels. Macromolecules 2009, 42, 84438450 .

42 34. Vonarbourg, A.; Passirani, C.; Saulnier, P.; Simard, P.; Leroux, J. C.; Benoit, J. P., 43 Evaluation of Pegylated Lipid Nanocapsules Versus Complement System Activation and 44 Macrophage Uptake. J. Biomed. Mater. Res. 2006, 78, 620-8.

45 35. Vonarbourg, A.; Passirani, C.; Saulnier, P.; Benoit, J. P., Parameters Influencing the 46 Stealthiness of Colloidal Drug Delivery Systems. Biomaterials 2006, 27, 4356-73. 
36. Harashima, H.; Huong, T. M.; Ishida, T.; Manabe, Y.; Matsuo, H.; Kiwada, H., Synergistic Effect between Size and Cholesterol Content in the Enhanced Hepatic Uptake Clearance of Liposomes through Complement Activation in Rats. Pharm. Res. 1996, 13, 1704-9. 37. Karim, R.; Palazzo, C.; Laloy, J.; Delvigne, A. S.; Vanslambrouck, S.; Jerome, C.; Lepeltier, E.; Orange, F.; Dogne, J. M.; Evrard, B.; Passirani, C.; Piel, G., Development and Evaluation of Injectable Nanosized Drug Delivery Systems for Apigenin. Int. J. Pharm. 2017, 532, 757-768.

38. Paillard, A.; Hindre, F.; Vignes-Colombeix, C.; Benoit, J. P.; Garcion, E., The Importance of Endo-Lysosomal Escape with Lipid Nanocapsules for Drug Subcellular Bioavailability. Biomaterials 2010, 31, 7542-54.

39. Avelar-Freitas, B. A.; Almeida, V. G.; Pinto, M. C. X.; Mourão, F. A. G.; Massensini, A. R.; Martins-Filho, O. A.; Rocha-Vieira, E.; Brito-Melo, G. E. A., Trypan Blue Exclusion Assay by Flow Cytometry. Braz. J. Med. Biol. Res. 2014, 47, 307-3015.

40. Patino, T.; Soriano, J.; Barrios, L.; Ibanez, E.; Nogues, C., Surface Modification of Microparticles Causes Differential Uptake Responses in Normal and Tumoral Human Breast Epithelial Cells. Sci. Rep. 2015, 5, 11371.

41. Lepinoux-Chambaud, C.; Barreau, K.; Eyer, J., The Neurofilament-Derived Peptide Nf1Tbs.40-63 Targets Neural Stem Cells and Affects Their Properties. Stem Cells Transl. Med. 2016, 5, 901-13.

42. Patrick, J. W.; Gamez, R. C.; Russell, D. H., The Influence of Lipid Bilayer Physicochemical Properties on Gramicidin a Conformer Preferences. Biophys. J. 2016, 110, 1826-1835.

43. Sahay, G.; Alakhova, D. Y.; Kabanov, A. V., Endocytosis of Nanomedicines. J. Control. Release 2010, 145, 182-95.

44. Laine, A.-L.; Clavreul, A.; Rousseau, A.; Tétaud, C.; Vessieres, A.; Garcion, E.; Jaouen, G.; Aubert, L.; Guilbert, M.; Benoit, J.-P., Inhibition of Ectopic Glioma Tumor Growth by a Potent Ferrocenyl Drug Loaded into Stealth Lipid Nanocapsules. Nanomedicine 2014, 10, 16671677.

45. Karim, R.; Somani, S.; Al Robaian, M.; Mullin, M.; Amor, R.; McConnell, G.; Dufes, C., Tumor Regression after Intravenous Administration of Targeted Vesicles Entrapping the Vitamin E A-Tocotrienol. J. Control. Release 2017, 246, 79-87.

46. Bastiancich, C.; Vanvarenberg, K.; Ucakar, B.; Pitorre, M.; Bastiat, G.; Lagarce, F.; Preat, V.; Danhier, F., Lauroyl-Gemcitabine-Loaded Lipid Nanocapsule Hydrogel for the Treatment of Glioblastoma. J. Control. Release 2016, 225, 283-93.

47. Cajot, S.; Lautram, N.; Passirani, C.; Jerome, C., Design of Reversibly Core CrossLinked Micelles Sensitive to Reductive Environment. J. Control. Release 2011, 152, 30-6. 48. Gao, H., Perspectives on Dual Targeting Delivery Systems for Brain Tumors. $J$. Neuroimmune Pharmacol. 2017, 12, 6-16. 


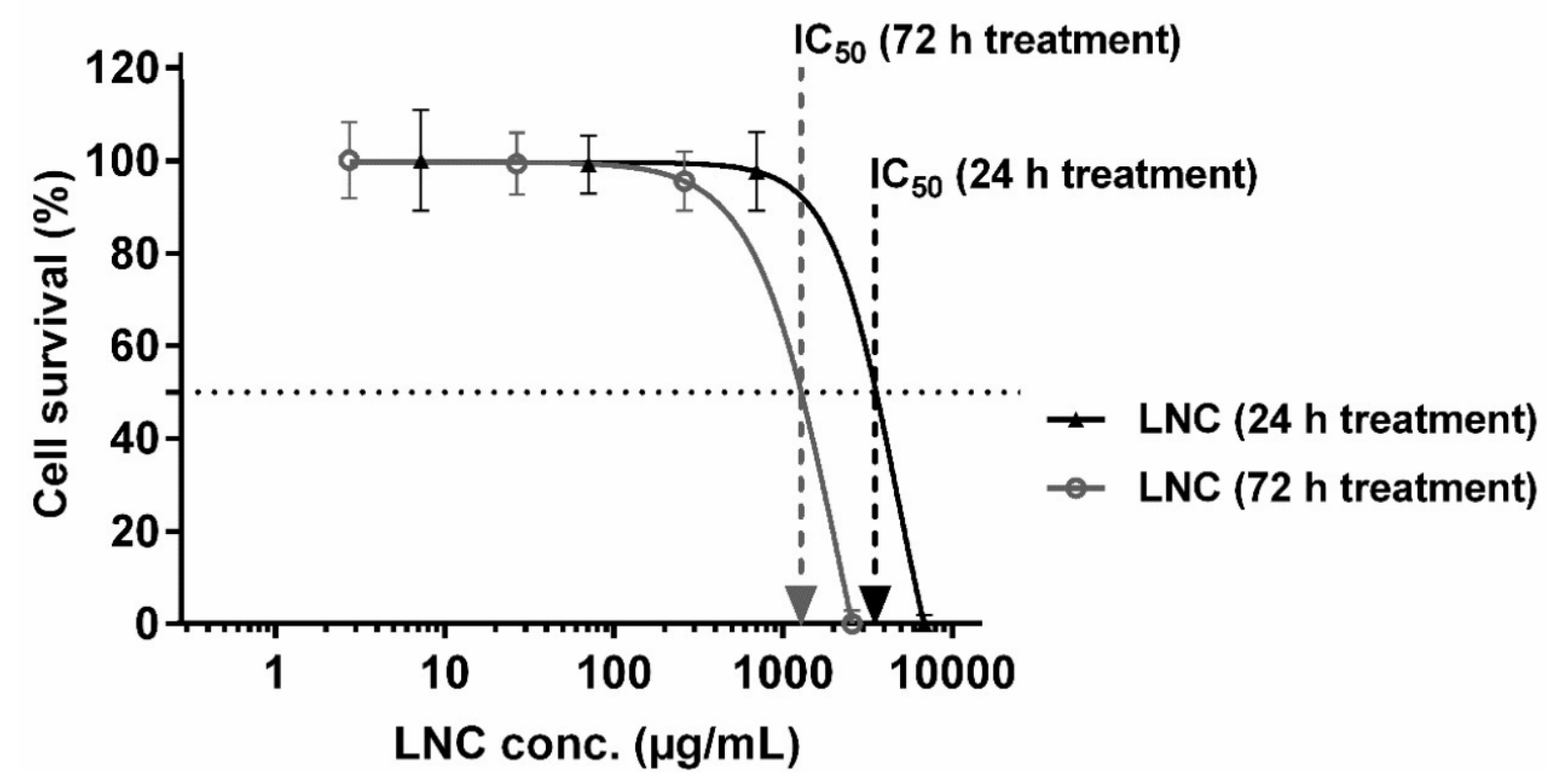

7 Figure S1. Survival percentages of U87MG cells after $24 \mathrm{~h}$ and $72 \mathrm{~h}$ treatment with 8 various concentrations of blank LNCs. 


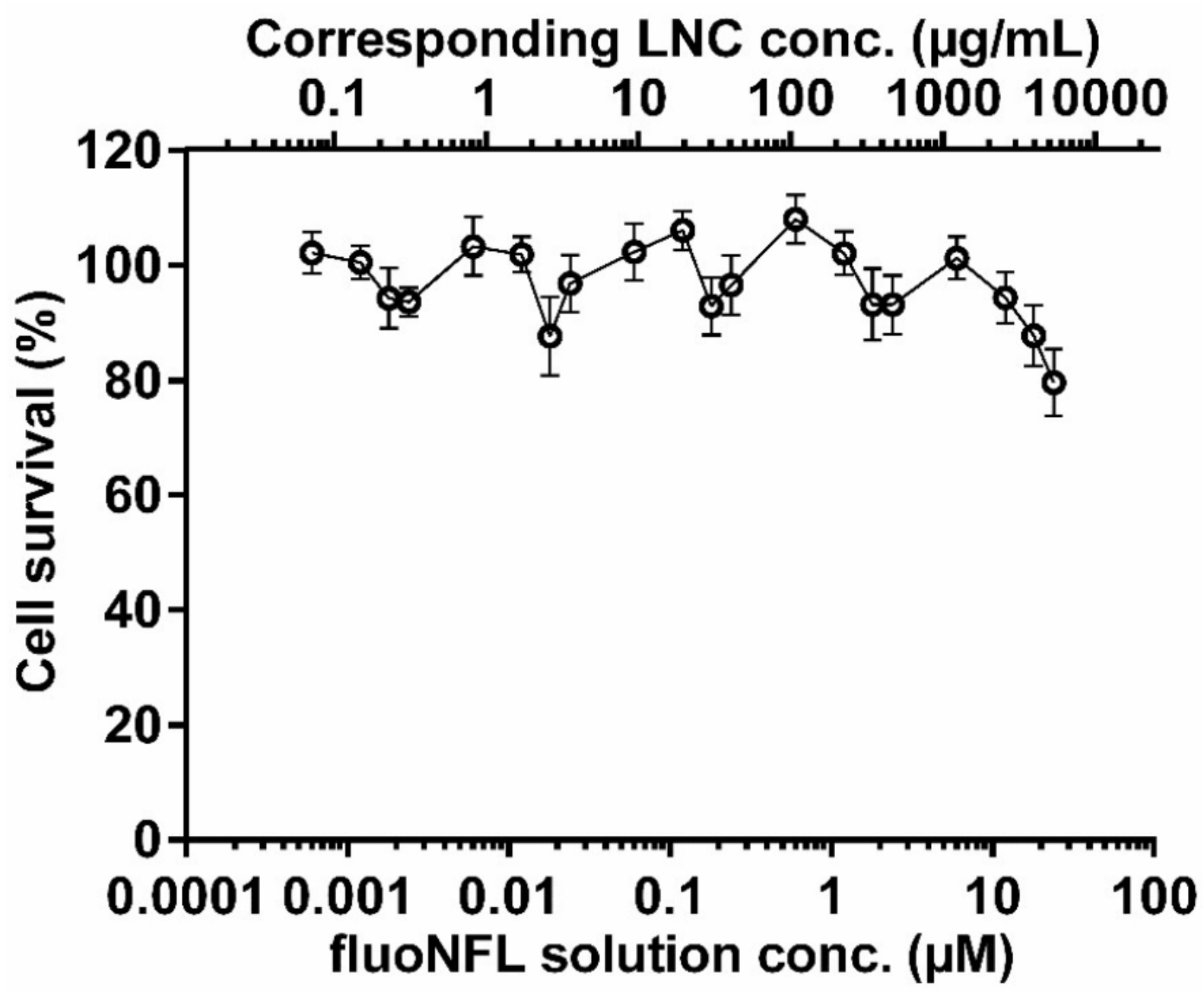

2 Figure S2. Survival percentages of U87MG cells after $72 \mathrm{~h}$ treatment with various 3 concentrations fluoNFL solution. 

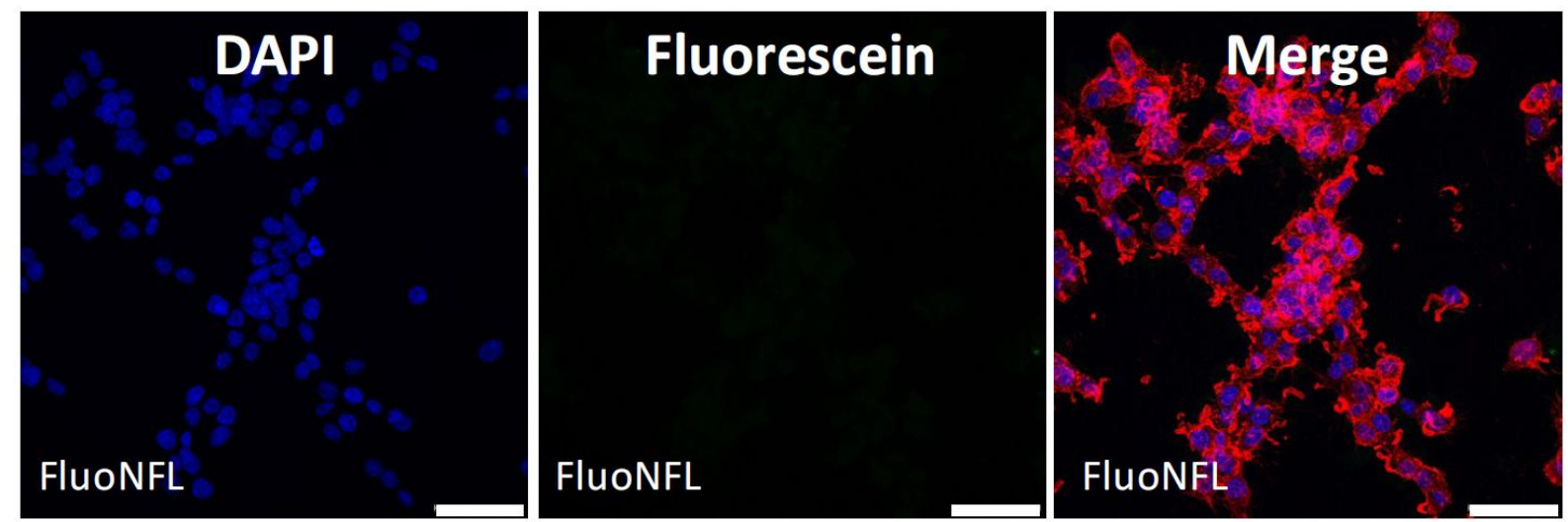

3 Figure S3. Representative confocal microscopy images of fluoNFL internalization into 4 U87MG. Cells were treated at $37^{\circ} \mathrm{C}$ for $6 \mathrm{~h}$ with $1 \mu \mathrm{M}$ of fluoNFL. Blue is DAPI staining 5 (nuclei), green is carboxyfluorescein (fluoNFL) and red is phalloidin-TRITC staining (F6 actin, cytoskeleton). White bar $=50 \mu \mathrm{m}$.
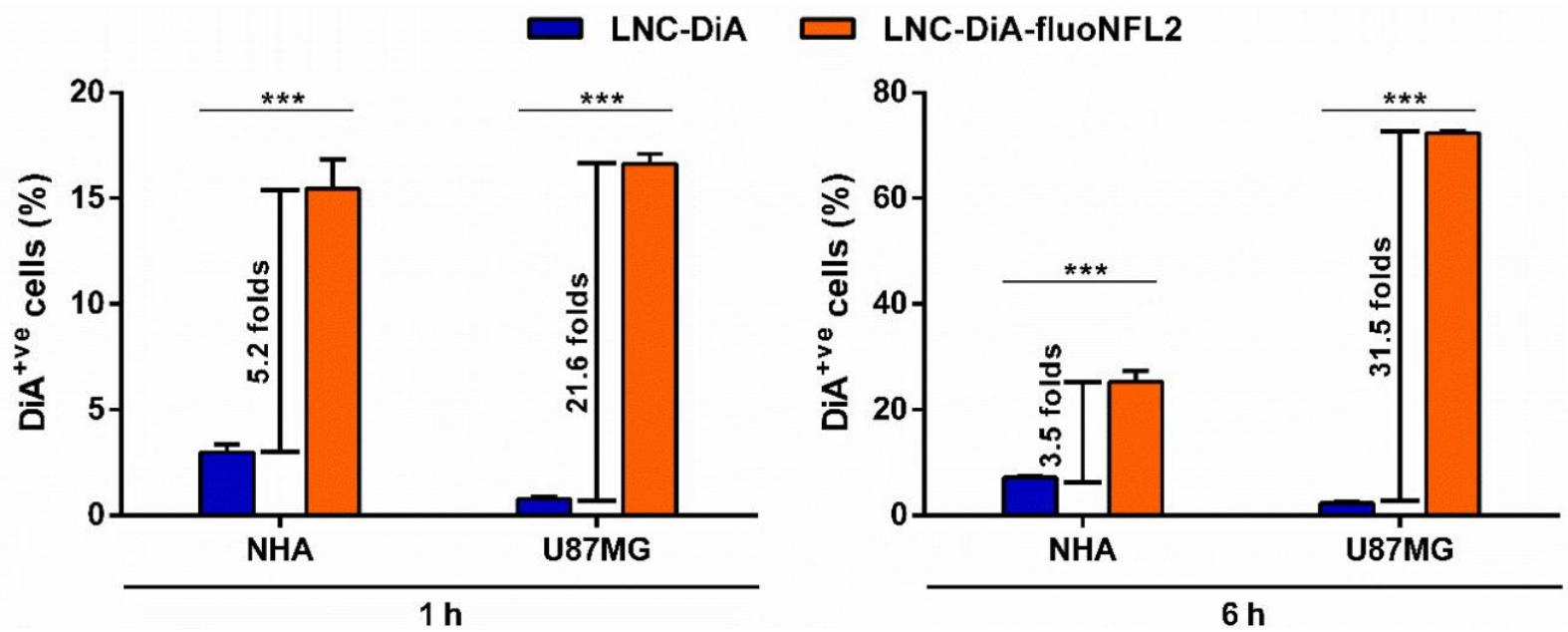

9 Figure S4: Enhanced LNC Internalization into NHA and U87MG cells due to LNC

10 surface functionalization using fluoNFL peptide. The cells were incubated with 1.23

$11 \mathrm{mg} / \mathrm{mL}$ of LNCDiA and LNC-DiA-fluoNFL2 for $1 \mathrm{~h}$ and $6 \mathrm{~h}$. Twenty thousand events per

12 sample were analyzed and percentages of $\mathrm{DiA}^{\text {tve }}$ cells were measured. The

13 experiments were performed in triplicate. Statistical analysis was performed with t-test

$14 \quad\left(p<0.05\right.$ is denoted by $\left({ }^{*}\right), p<0.01$ by $\left({ }^{* *}\right)$ and $p<0.001$ by $\left.\left({ }^{* * *}\right), n=3\right)$. 